\title{
"No hay QUe tolerar a AQUEllos QUE CON BOCA DE PERRO INTENTAN HABLAR MAL DE LAS MUJERES": Alonso de Cartagena, la cuarta Cuestión del DUODENARIUM Y LA QUERELla DE LAS MUJERES
}

\author{
Rita Ríos de la Llave ${ }^{1}$ \\ Universidad de Alcalá
}

Recibido: 29 de junio de 2017

Aceptado: 22 de septiembre de 2017

\begin{abstract}
Resumen
El objetivo del presente trabajo es demostrar, a través del análisis de la cuarta cuestión del Duodenarium de Alonso de Cartagena, la participación de este último en la Querella de las mujeres. Para ello se analizan los temas abordados por el autor, que pretende rebatir a los autores que critican a las mujeres, y se compara su pensamiento con el de otros autores que participaron en el debate, como Giovanni Boccaccio, Juan Rodríguez del Padrón, Diego de Valera, Álvaro de Luna y Teresa de Cartagena. Finalmente, se lleva a cabo una valoración del pensamiento de Alonso de Cartagena a través de las diversas formas de entender el concepto de mujer enunciadas por Prudence Allen.
\end{abstract}

\section{Palabras clave}

Querella de las mujeres; Alonso de Cartagena; Duodenarium; concepto de mujer; defensa de las mujeres.

\begin{abstract}
The objective of this paper is to demonstrate, through the analysis of the fourth issue of the Duodenarium written by Alonso de Cartagena, his participation in the Woman Question. In order to do so, I analyse the themes addressed by the author, who pretends to refute those who criticize women, and I compare his ideas to those of other authors participating in the debate, such as Giovanni Boccaccio, Juan Rodríguez del Padrón, Diego de Valera, Álvaro de Luna, and Teresa de Cartagena. I finally carry out an assessment of Alonso de Cartagena's thought through the various ways of understanding the concept of woman enunciated by Prudence Allen.
\end{abstract}

\section{Keywords}

Woman Question; Alonso de Cartagena; Duodenarium; concept of woman; women defense.

\section{Résumé}

Le but de cette étude est de mettre en évidence, à travers l'analyse de la quatrième question du Duodenarium d'Alonso de Cartagena, la part qu'a prise cet auteur dans la Querelle des femmes. Pour ce faire, nous avons analysé les questions abordées par l'auteur, qui cherche à réfuter ceux qui

1 Correo electrónico: rita.rios@uah.es. ORCID: https://orcid.org/0000-0001-7729-0155. 
critiquent les femmes, et nous comparons sa pensée avec celui d'autres auteurs qui participèrent au débat, comme Boccace, Juan Rodríguez del Padrón, Diego de Valera, Álvaro de Luna et Teresa de Cartagena. Enfin, nous avons procédé à une évaluation de la pensée d'Alonso de Cartagena, á travers les différentes façons de comprendre le concept de femme énoncées par Prudence Allen.

\section{Mots-clé}

Querelle des femmes; Alonso de Cartagena; Duodenarium; le concept de femme; défense des femmes.

\section{Introducción}

El primer intento serio de hacer frente al pensamiento misógino y denunciar la desigualdad impuesta a las mujeres se llevó a cabo en la Europa occidental en el marco de la Querella de las mujeres. Este debate literario con implicaciones políticas, filosóficas y teológicas, que se extendió desde el siglo XIII hasta la aparición del feminismo, fue el marco en el que se enfrentaron defensores y detractores de las mujeres y en el que se abordaron temas tales como la naturaleza, el valor, las virtudes y las capacidades de las mujeres, así como las relaciones de los sexos y entre los sexos ${ }^{2}$.

La implicación de los autores y autoras hispánicos en la Querella de las mujeres fue abordada ya en el siglo XIX, bajo la denominación de "Debate sobre la mujer", por Amador de los Ríos y Menéndez Pelayo³ . A ellos se sumaron María Pilar Oñate en 1938 y Jacob Ornstein en 1941, el cual puso de manifiesto que llegó a Cataluña en pleno siglo XIII (aunque M. ${ }^{a}$ del Pilar Rábade Obradó lo retrasa al siglo XIV), y a Castilla en el siglo $\mathrm{XV}^{4}$. Aunque también hay quien cuestiona la existencia de un debate en torno a la mujer en la España del siglo XV, puesto que no hubo un verdadero intercambio de ideas y argumentos ${ }^{5}$ En cualquier caso, Oñate presentó una relación de obras literarias

\footnotetext{
Rivera Garretas, Textos y espacios de mujeres. Europa siglos $I V$-XV, pp. 46, 155, 184-186. Rivera GARRETAS (coord.), Las relaciones en la Historia de la Europa medieval, pp. 46-51.

3 Véase una descripción acerca de la investigación sobre la Querella de las mujeres en el ámbito hispánico en DE VALERA, Defensa de virtuosas mujeres, pp. 55-131.

4 OÑATE, El feminismo en la literatura española. ORNSTEIN, "La misoginia y el profeminismo en la literatura castellana", pp. 220-221. RÁBADE OBRADÓ, "El arquetipo femenino en los debates intelectuales del siglo XV castellano", p. 262.

5 Es el caso de Pamela Benson, quien señala que los autores de los textos misóginos no pretendían convencer, sino que se limitaban a reproducir ideas ya asentadas (BENSON, "Debate about women in Trecento Florence", p. 165). También Robert Archer, quien considera que las obras en las que se defiende a las mujeres no son fruto de un debate local, sino que proceden de la tradición europea (ARCHER, The Problem of Woman in LateMedieval Hispanic Literature, pp. 6, 123 y 203-204). Por su parte, Julio Vélez-Sainz denuncia que "poco debate hubo (si alguno) sobre la naturaleza de la mujer" (VÉLEZ-SAINZ, La defensa de la mujer en la literatura hispánica. Siglos XV-XVII, p. 22). E igualmente Federica Accorsi, quien destaca que, mientras que los autores que hablaban a favor de las mujeres lo hacían para desautorizar a los autores misóginos, estos últimos no se hicieron eco de la polémica y se limitaron a atacar a las mujeres (DE VALERA, Defensa..., p. 191). Así pues, no resulta extraño, tal y como ha señalado Julien Weiss, que "The Spanish debate over woman has often been called a courtly entertainment, or a literary «game»" (WeIss, “"¿Qué demandamos de las mugeres?»: Forming the Debate about Women in Late Medieval Spain (with a baroque response)", p. 244).
} 
favorables a las mujeres, mientras que Ornstein optó por un listado que incluía tanto tratados misóginos como propicios a las mujeres. Un registro que se ha ido incrementando con el paso de los años, a medida que ha ido avanzando la investigación relativa a la misoginia y la defensa de las mujeres, o el "antifeminismo" y el "profeminismo", según la terminología utilizada tradicionalmente ${ }^{6}$.

Dentro del inventario de obras favorables a las mujeres a veces se menciona un Libro de las mujeres ilustres elaborado por el humanista Alonso de Cartagena ${ }^{7}$, y que se trata, en realidad, de una atribución falsa ${ }^{8}$. Julian Weiss y Federica Accorsi se han referido asimismo a la defensa de las mujeres que el mismo autor hizo en las glosas que forman parte de su Copilación de algunos dichos de Séneca, fechadas entre 1430 y 1434, y que, en opinión de Accorsi, podrían ser los primeros ejemplos contrarios a la misoginia en la literatura castellana9. Pero suele pasar desapercibida la respuesta que Alonso de Cartagena dio en el Duodenarium a la cuarta cuestión presentada por su amigo Fernán Pérez de Guzmán: "Quis mirabilior, laudabilior ac melior reputari debet, optimus vir an optima mulier?" "“QQuién debe ser considerado más admirable, más loable y mejor: un hombre óptimo o una mujer óptima?"). Una situación que pretendemos paliar con el presente trabajo, que hemos llevado a cabo a partir de la edición y traducción del Duodenarium realizadas por Luis Fernández Gallardo y Teresa Jiménez Calvente ${ }^{10}$.

\footnotetext{
6 Montoya Ramírez, "Observaciones sobre la defensa de las mujeres en algunos textos medievales", vol. 3, pp. 397-406, especialmente pp. 397 y 399. Solomon, The Literature of Misogyny in Medieval Spain. The Arcipreste de Talavera and the Spill. WeIss, “¿QQué demandamos...?»”, pp. 237-281, especialmente pp. 275-281. Archer, Misoginia y defensa de las mujeres. Antología de textos medievales. ArCher, The Problem... Fenster y Lees, "Bibliography of Primary Texts in Spanish, ca. 1430-1520", pp. 275-281. VéLeZSAINZ, La defensa ..., pp. 13-27, donde se analiza el corpus presentado por diferentes autores y el autor ofrece también el suyo propio. Vargas Martínez, La Querella de las mujeres. Tratados hispánicos en defensa de las mujeres (siglo $\mathrm{XV}$ ).

7 Oñate, El feminismo..., p. 52. Ornstein, "La misoginia...", pp. 221 y 223. Cantera Burgos, Alvar García de Santa María y su familia de conversos. Historia de la Judería de Burgos y de sus conversos más egregios, p. 464. DE LunA, Virtuosas e claras mugeres (año 1446), p. 38. Pelaz Flores, "«A la más virtuosa de las mujeres». La reina María de Aragón (1420-1445) como impulsora de las letras en la Corona de Castilla", p. 337. Vargas Martínez, La Querella..., p. 29.

8 Véase a este respecto Morrás Ruiz-Falcó, "Repertorio de obras, manuscritos y documentos de Alfonso de Cartagena (ca. 1384-1456)", pp. 235-236. DE CARTAgena, Doctrinal de los caballeros, p. XXXVI. Hernández Amez, "Mujer y santidad en el siglo XV: Álvaro de Luna y El Libro de las Virtuosas E Claras Mugeres", p. 282, que recoge las opiniones al respecto de Arturo Farinelli y Agustín Boyer. Y principalmente los trabajos de Federica Accorsi: de Valera, Defensa ..., pp. 56-57. Accorsi, "La influencia de Alfonso de Cartagena en la Defensa de virtuosas mujeres de Diego de Valera", p. 21.

9 Weiss, “«¿Qué demandamos...?»”, p. 276. AcCorsi, "La influencia...”, pp. 16-18, 20 y 22.

10 Fernández Gallardo y Jiménez Calvente, El Duodenarium (c. 1442) de Alfonso de Cartagena. Cultura castellana y letras latinas en un proyecto inconcluso. La cuarta cuestión aparece desarrollada desde las pp. 384-385 hasta las pp. 480-481. A partir de ahora, cuando hagamos referencia a la opinión de los editores, se hará referencia a los mismos de forma específica, mientras que, cuando se mencionen las ideas expresadas por Alonso de Cartagena, se citará Duodenarium, seguido de la cuestión en números romanos y del capítulo en números arábigos.
} 
Fernán Pérez de Guzmán planteaba la cuestión en un momento en el que la Querella de las mujeres estaba en plena efervescencia en la corte castellana, donde la reacción contra los autores misóginos (entre ellos el capellán real Alfonso Martínez de Toledo), habría sido encabezada por la reina María de Aragón (1403-1445), primera esposa de Juan II de Castilla (1405-1454), y las mujeres de su entorno, si bien la participación directa de la soberana es una cuestión que no todos los investigadores aceptan ${ }^{11}$. En cualquier caso, fue en este contexto en el que Juan Rodríguez del Padrón o de la Cámara le dedicó su Triunfo de las donas (1438-1441) ${ }^{12}$; Alonso de Cartagena redactó la cuarta cuestión del Duodenarium (1442); Diego de Valera ofreció a la reina su Defensa de virtuosas mujeres (1443-1444) ${ }^{13}$; y poco después salió a la luz las Virtuosas e claras mujeres (1446) de Álvaro de Luna ${ }^{14}$. Obras en las que se llevó a cabo una reflexión sobre los

11 En contra de la participación de la reina en el debate se presentan Robert Archer y también Federica Accorsi en su edición de la obra de Diego de Valera (Archer, The Problem ..., pp. 129-130. de VAlera, Defensa ..., pp. 56-57). A favor de su participación se manifiesta Ana Vargas Martínez en la reciente publicación de su tesis doctoral (Vargas Martínez, La Querella ..., pp. 27-30, 70, 75, 88-89 y 115), así como Diana Pelaz Flores, quien, considerando que "también ha de entenderse como autora intelectual aquella a la que el autor factual, el escritor o escritora, ha decidido dedicarle su obra, puesto que, en cierta manera, ha sido la causa que ha propiciado que el escrito se llevara a término" (Pelaz Flores, "«A la más virtuosa...»", p. 335), resalta que la propia "María de Aragón habría impulsado un movimiento destinado a frenar o mitigar esa visión peyorativa, al albor del renacimiento cultural gestado en la corte de Juan II" (ibídem, p. 337), lo que habría permitido no sólo resaltar las virtudes de las mujeres en general, sino también las de la propia soberana (ibídem, p. 339), que se convertiría en "espejo de las mujeres" (ibídem, p. 341).

12 Rodríguez del Padrón, Obras Completas, pp. 211 y 253-254. Sobre el Triunfo de las donas y la relevancia política de las dedicatorias de obras a la reina véase SERrano, "La cuestión de la mujer y de la nobleza en la corte de Juan II de Castilla a la luz de los tratados de Juan Rodríguez del Padrón", vol. 2, pp. 1.667-1.679. Sobre la relevancia de la obra de Juan Rodríguez del Padrón en la Querella de las mujeres véase Vélez-Sainz, La defensa ..., pp. 93-119. Vargas Martínez, La Querella ..., pp. 122-131.

13 Frente a la fecha tradicional asignada a la obra de Valera (c. 1445), Federica Accorsi señala como marco cronológico verosímil de redacción entre 1439 y 1441 (DE VALERA, Defensa..., p. 16), aunque más adelante se inclina por el período 1435-1436 (ibídem, p. 63), que igualmente figura en ACCORSI, "La influencia...", pp. 21-22. Pero nos parecen más sólidos los argumentos esgrimidos por Florence Serrano, quien sitúa la elaboración de esta obra en el período 1443-1444 (SERRANo, "Figures auctoriales et figures du pouvoir: Valera et Rodríguez del Padrón à la cour de Bourgogne", p. 116. Serrano, "Del debate de la propaganda política mediante la Querella de las mujeres en Juan Rodríguez del Padrón, Diego de Valera y Álvaro de Luna", p. 98, nota 3). Sobre la relevancia de la obra de Valera dentro de la Querella de las mujeres véase Vélez-sainz, La defensa ..., pp. 121-142. Vargas Martínez, La Querella ..., pp. 131-137.

14 Manuel Castillo y Agustín Boyer consideran que la obra de Álvaro de Luna también podría haber estado destinada a ser dedicada a la reina María de Aragón, algo que no se habría concretado por la muerte de la misma en 1445. Asimismo, Agustín Boyer también ha planteado la posibilidad de que Álvaro de Luna tuviera la intención de ofrecérsela a su hija, María de Luna (citados por Hernández Amez, "Mujer...", pp. 265, 282 y 285). Por su parte, Abby McGovern afirma que Álvaro de Luna habría escrito su obra para mostrar a la soberana cómo debía comportarse (McGovern, "Writing the Antithesis of María of Aragón: Alvaro de Luna's Rendering of Giovanni Boccaccio's De mulieribus claris", pp. 327 y 334). Sobre la relevancia de la obra de Álvaro de Luna en la Querella de las mujeres véase VéLEZ-SAINZ, La defensa ..., pp. 93-119. VARgas Martínez, La Querella..., pp. 61-92 y 137-145. 
diversos modelos femeninos ${ }^{15}$, sobre distintas cuestiones relacionadas con los problemas políticos del momento ${ }^{16} \mathrm{y}$ sobre aspectos relacionados con algunos debates culturales ${ }^{17}$. Así pues, la respuesta de Alonso de Cartagena a la cuarta cuestión del Duodenarium no tendría un destinatario único, Fernán Pérez de Guzmán, sino que se enmarcaría dentro del debate general que estaba teniendo lugar en esos momentos. Y él no sólo pretendería dar respuesta a Fernán Pérez de Guzmán, sino también a los autores misóginos, "a aquellos que con boca de perro intentan hablar mal de las mujeres"18. A diferencia de Federica Accorsi, que piensa que "non può essere considerato parte del debate"1, pensamos que se trata de un texto relevante para comprender el desarrollo de la Querella de las mujeres en el ámbito castellano, y de ahí que hayamos realizado un análisis de esta cuestión, y de otras reflexiones relacionadas con los temas de la Querella que se ubican en diferentes secciones de la obra, estableciendo comparaciones tanto con el De mulieribus claris (1361-c. 1375) de Giovanni Boccaccio como con otras obras del ámbito castellano, concretamente el Triunfo de las donas de Juan Rodríguez del Padrón, la Defensa de virtuosas mujeres de Diego de Valera, Virtuosas e claras mujeres de Álvaro de Luna y la Admiraçión operum Dey, una de las obras escritas por Teresa de Cartagena, sobrina del propio Alonso ${ }^{20}$.

15 Pelaz Flores, “"A la más virtuosa...»”, p. 334.

16 Diana Pelaz Flores ha puesto de manifiesto cómo algunas de las obras proponen diferentes modelos de actuación política para la soberana (Pelaz Flores, “«A la más virtuosa...»”, pp. 344-345). Este tema también ha sido desarrollado por Florence Serrano, quien destaca que en las obras de Juan Rodríguez del Padrón, Diego de Valera y Álvaro de Luna se "propone un "programa" político para la crisis que empezó en la década de los treinta y que solo se solucionaría con la batalla de Olmedo (1445), marcando la derrota de los Infantes de Aragón y el (fugaz) triunfo de Álvaro de Luna" (SERrano, "Del debate...", p. 99). En su opinión, Rodríguez del Padrón se muestra favorable al bando de los Infantes de Aragón, solicitando la intervención de la reina, mientras que Valera se inclina por una "visión apolítica" y Álvaro de Luna trata de legitimar su posición y limitar el papel de la soberana (ibídem, pp. 109 y 112). Sobre el papel clave de la política sexual durante los reinados de Juan II, Enrique IV e Isabel la Católica véase un breve resumen en WeIss, “«QQué demandamos...?»”, pp. 237-281, especialmente pp. 239-240.

17 Sobre la relación de algunas obras de la Querella con el debate entre cultura clerical y cultura laica, o el relativo a las armas y las letras véase Weiss, "«¿Qué demandamos...?»”, pp. 244 y 249-250. Este autor igualmente pone de manifiesto que "the debate is also inextricably intertwined with a range of other ideologies that structured social castes and classes, notions of race, morality or medicine, or such practices as courtliness and the literary (...)" (ibídem, p. 242). Sobre la vinculación entre el debate sobre las mujeres y el de la nobleza véase Serrano, "La cuestión...", pp. 1.668-1.679. Sobre el carácter didáctico de los tratados escritos en defensa de las mujeres véase HernÁNDEZ Amez, "Mujer...", p. 287 y sobre su instrumentalización por parte de las mujeres de la alta aristocracia véase Pelaz Flores, "«A la más virtuosa...»", p. 349.

18 Duodenarium, IV, 3, p. 391.

19 De Valera, Defensa ..., p. 78, nota 63.

20 Existe diversidad de opiniones con respecto a la datación de las obras de Teresa de Cartagena, la Arboleda de los enfermos y la Admiraçión operum Dey, que hemos consultado en la versión editada (DE Cartagena, Arboleda de los enfermos. Admiraçión operum Dey). Según Francisco Cantera Burgos, la primera de ellas fue escrita entre 1453 y 1460 (CANTERA Burgos, Alvar García..., pp. 541-546). Dayle Seidenspinner-Núñez y Yonsoo Kim, por su parte, la fechan hacia 1475-1476 (SEIDENSPINNER-NunEz, The Writings of Teresa de Cartagena, p. IX. КІм, El saber femenino y el sufrimiento corporal de la temprana Edad Moderna. Arboleda de los enfermos y Admiraçión operum Dey de Teresa de Cartagena, p. 46), mientras que James Hussar cree que fue escrita hacia 1477-1478 (Hussar, "The Jewish Roots of Teresa 


\section{Alonso de Cartagena y el Duodenarium}

Alfonso García de Santa María (c. 1385-1456), también conocido como Alonso de Cartagena, era hijo de Salomón Haleví o Shlomo Ha-Leví (c. 1353-1435), rabino mayor de la aljama de Burgos, que se convirtió al cristianismo con el nombre de Pablo de Santa María cuando él todavía era un niño. Estudió Derecho Civil y Canónico en la Universidad de Salamanca y ocupó diversos cargos eclesiásticos: canónigo en Salamanca desde 1414, deán de Compostela desde 1415, nuncio apostólico y colector general desde 1417, y deán de Segovia desde 1418. Al mismo tiempo iniciaba su carrera política en el entorno del infante Juan de Aragón y durante la minoridad del rey Juan II de Castilla (1406-1420): se convirtió en oidor de la Audiencia en algún momento entre 1410 y 1415, miembro del Consejo Real a partir de 1421, embajador ante la corte de Portugal entre 1421 y 1426 al servicio de los intereses de Álvaro de Luna (aunque evitó que le afectase su caída en desgracia en 1453), privado de Juan II y oidor en la frontera de Granada desde 1431. Entre 1434 y 1440 asistió al Concilio de Basilea, como miembro de la segunda embajada castellana, y defendió los derechos de prelación de los castellanos sobre los ingleses a través de su discurso De preeminentia (1434), lo que le proporcionó éxito y fama. Igualmente defendió los derechos de Castilla sobre las islas Canarias frente a Portugal (1437). En 1435 sucedía a su padre como obispo de Burgos. Más adelante, en 1438, fue enviado como embajador del rey castellano ante el emperador Alberto II, y en 1439, como legado del Concilio para mediar entre el emperador y el rey polaco Ladislao III, que disputaban

de Cartagena's Arboleda de los enfermos", pp. 151-154). La Admiraçión operum Dey es indudablemente una obra posterior a la Arboleda de los enfermos, en tanto en cuanto hace referencia a las críticas recibidas tras la difusión del otro tratado, y en cualquier caso es anterior al año 1481, fecha en la que Pero López de Trigo copió ambas obras en el manuscrito en el que han sobrevivido, y que se conserva en la biblioteca del Monasterio de El Escorial. Sobre la extensa bibliografía referida a la vida y obra de Teresa de Cartagena caben destacar, por orden cronológico, Deyermond, "El Convento de Dolencias: The Works of Teresa de Cartagena". Marimón Llorca, Prosistas castellanas medievales, pp. 102-134. Rivera Garretas, "La Admiración de las Obras de Dios de Teresa de Cartagena y la querella de las mujeres". Seidenspinner-Nunez, "«Él solo me leyó»: Gendered Hermeneutics and Subversive Poetics in Admiraçión operum Dey of Teresa de Cartagena". SuRTz, Writing Women in Late Medieval and Early Modern Spain. The Mothers of Saint Teresa of Avila, pp. 21-40. Rivera GARretas, "Teresa de Cartagena la infinitud del cuerpo". SeidenspinNER-NunEz y Kim, "Historicizing Teresa: reflections on new documents regarding Sor Teresa de Cartagena". CORTÉs TIMONER, Teresa de Cartagena, primera escritora mística en lengua castellana. Cortés Timoner, "«Poner riquezas en mi entendimiento»: Sor Juana Inés de la Cruz y Sor Teresa de Cartagena". Rivera Garretas, "Teresa de Cartagena vivía en 1478". Rivera Garretas, "Una vida en relación: Juana de Mendoza con Gómez Manrique, Isabel La Católica y Teresa de Cartagena". Ríos de la Llave, "Forget Your People and Your Father's House: Teresa de Cartagena and the Converso Identity". Rivera Garretas, "Los dos infinitos en Teresa de Cartagena, humanista y mística del siglo XV". Kim, Between Desire and Passion: Teresa de Cartagena. Rivera Garretas, "La documentación de Teresa de Cartagena en Santa Clara de Burgos (1446-1452) y otros datos". VéLEz-SAINZ, La defensa..., pp. 299 y 327-333. KIM, "Representación de la ansiedad masculina como discurso de santidad en Teresa de Cartagena". Kim y Carvajal, "La codificación de la espiritualidad femenina de Teresa de Cartagena y Santa Teresa de Ávila”. CORTÉs Timoner, "«Fue levado mi entendimiento»: Teresa de Cartagena y la escritura mística en femenino”. Vargas MarTínez, La Querella..., pp. 165-174. 
por la corona de Bohemia. Es probable que oficiara los funerales de la reina María en la catedral de Burgos en abril de 1445 y dirigió en 1455 el traslado de los restos del rey Juan II desde el convento de San Pablo de Valladolid hasta el monasterio de Las Huelgas en Burgos. Su carrera literaria, en latín y castellano, se inició durante su estancia en Portugal, donde empezó a formar su biblioteca y entró en contacto con el humanismo, mientras que durante el Concilio de Basilea profundizó en sus relaciones con los intelectuales humanistas. Entre 1444 y 1448 redactó el Doctrinal de los caballeros y en 1449 apareció su obra más renombrada, el Defensorium unitatis christianae, en respuesta a la Sentencia-estatuto de Pero Sarmiento, en defensa de los conversos y al servicio de la monarquía, mientras que entre 1454 y 1456 escribió una obra histórica acerca de los reyes de España, la Anacephaleosis ${ }^{21}$.

El Duodenarium fue redactado por Alonso de Cartagena tras su regreso de Basilea, a petición de Fernán Pérez de Guzmán (ca. 1377-1460), Señor de Batres, sobrino de Pero López de Ayala, tío del Marqués de Santillana, destacado poeta y prosista, y amigo de Alonso de Cartagena desde 1421, si bien ambos se habían posicionado en bandos distintos con relación a Álvaro de Luna. Pérez de Guzmán plantea doce cuestiones a Cartagena -de ahí el título de la obra, que adopta "los principios formales de una carta" 22 - Pero éste únicamente responde a cuatro de ellas entre enero y julio de 1442, agrupadas en dos binarios: si son idénticos los títulos real e imperial o uno precede al otro; cuántas lenguas ha habido; qué rey español aventajó en virtud a los demás; y si es superior la virtud masculina o la femenina ${ }^{23}$, cuyo análisis constituye el objetivo del presente trabajo.

La cuarta cuestión comprende 26 capítulos. Los cuatro primeros están dedicados a plantear lo que parece ser la conclusión principal de Alonso de Cartagena acerca de la comparación entre la virtud masculina y la virtud femenina: no quiere tomar partido ni a favor del hombre ni a favor de la mujer, y deja libertad de elección a su interlocutor, para lo cual procede a presentar tres parejas de hombres y mujeres entre los que poder escoger. La selección se lleva a cabo teniendo en cuenta una serie de rasgos, a fin de que haya variedad: antigüedad o modernidad (aunque ninguna de las parejas escogidas es contemporánea a la época de Alonso de Cartagena), origen gentil o católico, carácter nacional o extranjero y Ley de la Naturaleza o Ley de la Escritura:

21 Fernández Gallardo, Alonso de Cartagena. Una biografía politica en la Castilla del siglo XV, pp. $15,67,86-88,109,111,124,133,142,170,181-182,185,211,223,240-244,250-251$ y 281. FERNÁNDEZ Gallardo, La obra literaria de Alonso de Cartagena (1385-1456). Ensayo de historia cultural, pp. 9-12 y 159-166. Fernández Gallardo y Jiménez Calvente, El Duodenarium ..., pp. 42-46. Véase también Cantera Burgos, Alvar García..., pp. 416-487. Sobre el debate existente con relación a la vinculación de Alonso de Cartagena y el humanismo véase Morrás RuIz-FAlcó, "Sic et non: En torno a Alfonso de Cartagena y los studia humanitatis", pp. 335-339. También DI CAMILlo, El humanismo castellano del siglo XV, pp. 150-151 y 204-205. Di CAmillo, "Fifteenth-Century Spanish Humanism: Thirty-Five Years Later", pp. 21-23, 30-31 y 36.

22 Jiménez Calvente, “Alonso de Cartagena y la cuarta cuestión del Duodenarium: hacia un ensayo del género del diálogo", p. 135.

23 Fernández Gallardo y Jiménez Calvente, El Duodenarium ..., pp. 47-51. 


\begin{tabular}{|l|l|}
\hline PAREJA & RASGOS \\
\hline Catón el Joven - Lucrecia & - Antiguos \\
& - Gentiles \\
& - Extranjeros \\
& - Ley de la Naturaleza \\
\hline José - Susana & - Antiguos \\
& - Gentiles \\
& - Extranjeros \\
& - Ley de la Escritura \\
\hline Fernando III de Castilla y León - Berenguela & - Modernos \\
de Castilla & - Católicos \\
& - Nacionales \\
& - Ley de la Escritura \\
\hline
\end{tabular}

Cada una de las tres mujeres seleccionadas representa un estado civil: Lucrecia sería la mujer casada; Susana, la doncella; y la reina Berenguela, la viuda. Y dos de ellas suelen figurar en los catálogos de mujeres ilustres de otros autores que participan en la Querella de las mujeres: Lucrecia, que ya se hallaba en el De mulieribus claris de Giovanni Boccaccio, aparece en las obras de Diego de Valera y Álvaro de Luna, mientras que a Susana la encontramos en la obra de este último autor ${ }^{24}$. Pero no son las únicas mujeres que desfilan por la cuarta cuestión. A ellas se sumarán otras, entre ellas la Virgen María, considerada un modelo de virtud para todas las mujeres, que en el capítulo 1 de la cuarta cuestión es comparada tanto con la figura de Cristo como con la de Juan el Bautista, y que también suele ser recurrente en las obras de Diego de Valera, Juan Rodríguez del Padrón y Álvaro de Luna ${ }^{25}$.

Sin duda lo más original de la respuesta de Alonso de Cartagena es la comparación entre las diferentes parejas de hombre y mujer, y que se lleva a cabo a través de diálogos sucesivos, localizados entre el capítulo cinco y el capítulo diecinueve, y que Luis Fernández Gallardo considera rasgo propio del humanismo ${ }^{26}$. Dichos diálogos siguen siempre la misma pauta: comienza hablando el hombre, continúa la mujer, y después se repite la alternancia entre hombre y mujer, para, después de un breve comentario del propio Alonso de Cartagena, pasar a continuación a la siguiente pareja, por lo que Teresa Jiménez Calvente los considera, más bien, una sucesión de monólogos ${ }^{27}$. En cualquier caso, a través de ellos se va revelando la posición de Alonso de Cartagena en la Querella de las mujeres, tal y como expondremos a continuación. Por último, desde el capítulo veinte y hasta el capítulo veintiséis, Alonso de Cartagena presenta una especie de manual de la perfecta casada, que claramente constituye su ideal de mujer.

\footnotetext{
24 Boccaccio, Mujeres preclaras, p. 203. De Valera, Defensa..., pp. 237, 243 y 267-268. de Luna, Virtuosas..., pp. 252-255 (Susana) y 269-274 (Lucrecia).

25 de Valera, Defensa..., p. 250. Rodríguez del Padrón, Obras Completas..., pp. 237 y 243. de Luna, Virtuosas..., pp. 220-222.

26 Fernández Gallardo, “Alonso de Cartagena y la escritura humanística: epístola y diálogo”, pp. 75-76.

27 Jiménez Calvente, “Alonso de Cartagena...,", p. 145.
} 


\section{Los temas de la Querella abordados en la cuarta cuestión}

Uno de los temas habituales en la Querella es el que se refiere a la naturaleza de las mujeres. A este respecto Alonso de Cartagena considera que hombres y mujeres son distintos, "Y nadie en su sano juicio intentará hacer reproches a la Naturaleza"28. En este sentido sigue una idea tradicional entre los autores cristianos, la de que las reglas de la naturaleza han sido creadas por Dios, de tal manera que las diferencias existentes entre hombres y mujeres son algo eterno, existente más allá de la voluntad humana, sin posibilidad de elección, discusión o cambio ${ }^{29}$. Aunque también es verdad que admite que "uno y otro (sexo) han sido creados por Dios omnipotente y munífico, y que ambos están capacitados para el bien supremo y la gracia divina" ${ }^{30}$, una idea que también manifiesta Diego de Valera, y comparten Álvaro de Luna y Teresa de Cartagena ${ }^{31}$.

Especial atención se dedica en la Querella a las virtudes de las mujeres, y recordemos que el punto de partida de la cuarta cuestión del Duodenarium es una pregunta que pretende comparar al hombre más virtuoso con la mujer más virtuosa. Primeramente Alonso de Cartagena presenta a la Virgen María como modelo de virtud para todas las mujeres $^{32}$. A continuación, parece insinuar una oposición entre las virtudes propias de los hombres (vigor físico, audacia, fortaleza) y los vicios de las mujeres (blandura, debilidad, imprudencia, mezquindad), pero sobre todo distingue entre las virtudes de los hombres (fortaleza, audacia, justicia) y las virtudes de las mujeres (castidad, sosiego, tranquilidad, calma, pudicia, modestia), hasta el punto de que la existencia de esta diferenciación, en su opinión, dificulta la comparación entre hombres y mujeres, cuando él mismo reconoce la existencia de "mujeres viriles", esto es, de mujeres que asumen virtudes que considera propias de los hombres ${ }^{33}$, expresión que ya había utilizado Giovanni Boccaccio, y retomarán Diego de Valera y Álvaro de Luna ${ }^{34}$. Pero Cartagena insiste en que hay unas virtudes propias de los hombres y otras virtudes propias de las mujeres. Entre las virtudes femeninas, Alonso de Cartagena presta una especial atención a la castidad, que él considera la más importante, y que recomienda defender a toda costa, algo a lo que también se refieren Giovanni Boccaccio y Diego de Valera, si bien este último critica que se aplicase un rasero diferente a hombres y mujeres, exigiendo mayor castidad a las segundas que a los primeros ${ }^{35}$. Cartagena, en cambio, no duda en

\footnotetext{
28 Duodenarium, IV, 2, p. 391.

29 CoRfield, "History and the Challenge of Gender History", p. 243.

30 Duodenarium, IV, 1, p. 385.

31 De Valera, Defensa..., p. 287. de Luna, Virtuosas..., pp. 216-217. de Cartagena, Arboleda..., p. 129.

2 Duodenarium, IV, 1, p. 387.

3 Duodenarium, IV, 2, p. 389; 3, pp. 391 у 395; 4, pp. 395 у 397; 10, p. 417.

34 BocCACCIO, Mujeres preclaras..., pp. 67 (Semíramis es comparada a los varones esforzados), 153 (presenta como varones a las mujeres de los menios), 155 (Pentesilea actuó con virilidad), 184 (la fuerza viril de la reina Dido), 211 (Lena como varonil mujer), 218 (la audacia viril de Clelia) y 234 (el alma varonil de Artemisia). de VAlera, Defensa..., pp. 272 y 279. De Luna, Virtuosas ..., pp. 284-288 (Tanaquil), 307-310 (Claudia), 329-331 (Amesia), 345-346 (Pentesilea) y 380-381 (Zenobia).

35 Boccaccio, Mujeres preclaras..., pp. 90 y 180. DE Valera, Defensa ..., pp. 239, 244 y 287.
} 
culpabilizar a las propias mujeres que son víctimas de una violación, y a diferencia de Álvaro de Luna, que insistirá en que la culpa es del agresor, no de la víctima ${ }^{36}$. Pero, según Cartagena, la mujer debe resistirse, siguiendo el ejemplo de Lucrecia o el de Susana, aunque reprueba el suicidio cometido por la primera para evitar el deshonor ${ }^{37}$, y a diferencia de Álvaro de Luna, que lo considera mérito y martirio ${ }^{38}$. También insiste en que el comportamiento de las mujeres debe encaminarse a su conservación: "La dignidad en los vestidos, un caminar pausado, la abstinencia moderada de los alimentos, especialmente de la bebida, el apartarse de las reuniones masculinas, una prudente capacidad para mantenerse callada y el rubor van unidísimos a la castidad" ${ }^{\prime 9}$, palabras muy semejantes a las empleadas por Giovanni Boccaccio al presentar a Sulpicia, mujer de Fulvio Flaco ${ }^{40}$. Ante todo, las mujeres deben permanecer en silencio, tal y como había señalado San Pablo en la Carta primera a los corintios (14: 33-36). Aunque después Cartagena matiza su opinión al señalar que también los hombres severos deben abstenerse de las palabras y los comportamientos deshonestos. E igualmente quiere atenuar esa distinción a través de las tres parejas que cita como ejemplo, hombres y mujeres que, en su opinión, comparten las mismas virtudes: honestidad, austeridad y rigor en el caso de Catón el Joven y Lucrecia; castidad y fortaleza en el caso de José y Susana; mientras que equipara el ingenio y la pureza de Fernando III con la sabiduría, honestidad y castidad de Berenguela ${ }^{41}$. Pero la identificación entre las virtudes masculinas y las virtudes femeninas no llega a ser plena, porque Cartagena concluye en los tres casos que las virtudes del hombre superan a las de la mujer ${ }^{42}$.

La diferenciación entre virtudes masculinas y virtudes femeninas, por otro lado, le sirve a Alonso de Cartagena para establecer también una separación entre las funciones y tareas asignadas a hombres y mujeres: "La razón y la experiencia enseñan que el gobierno justo de la república, la defensa de los inocentes y el exterminio de los impíos -y nada hay más saludable que esto- son un oficio masculino"43; pues, "aunque haya muchas matronas honestas que dirigen los asuntos domésticos y familiares con muchísima prudencia, serían muy pocas las que habrían sabido gobernar prudentemente una república grande con la gravedad que convenía" ${ }^{44}$. Y también señala que "está claro que las acciones militares y conflictos bélicos, a cuya realización el vulgo

\footnotetext{
36 Así lo indica cuando, tras conocer la violación de Lucrecia por Sexto Tarquino, hace decir a los hombres que están con su marido que "ella non avía culpa mas el que la forçara, e que la voluntad fazía el pecado e non el cuerpo, e que donde non oviera consentimiento non avía culpa" (DE LunA, Virtuosas..., p. 271).

37 Duodenarium, IV, 5, p. 403; 14, p. 431.

38 DE LunA, Virtuosas..., pp. 254 y 272-273.

39 Duodenarium, IV, 3, p. 395.

40 Boccaccio, Mujeres preclaras..., pp. 260-261.

41 Duodenarium, IV, 5, p. 399 (Catón y Lucrecia); 10, p. 417 (José y Susana); 15, pp. 433, 435, 439 y 445 (Fernando III y Berenguela).

42 Véase de Catón el Joven sobre Lucrecia en Duodenarium, IV, 8, p. 411. Véase de José sobre Susana en Duodenarium, IV, 14, p. 427. Véase de Fernando III sobre Berenguela en Duodenarium, IV, 18, p. 445.

43 Duodenarium, IV, 3, p. 393.

44 Duodenarium, IV, 15, p. 435.
} 
atribuye una fortaleza extrema, no son apropiados para la honestidad femenina y la mujeril blandura" ${ }^{45}$, por lo que la guerra sería una función propia de los hombres ${ }^{46}$.

En consecuencia, y a diferencia de lo que opinaban Juan Rodríguez del Padrón o Álvaro de Luna, y en la línea de Giovanni Boccaccio, que no creía que las mujeres fueran aptas para gobernar, y ello a pesar de los ejemplos que presentaba ${ }^{47}$, Alonso de Cartagena afirma que las mujeres deben mantenerse apartadas del gobierno, el ejercicio de la justicia y la guerra, que él considera actividades propias de los hombres, lo que no le impide mostrar admiración por Berenguela, reina de Castilla y León ${ }^{48}$. Pero ella sería una excepción, como otros ejemplos de mujeres guerreras citadas (Ester, las amazonas y las mujeres escitas, las mujeres vizcaínas que luchaban junto a sus maridos y Juana de Arco $)^{49}$. Algunas de ellas son nombradas por otros autores, como Ester, a la que se refieren Juan Rodríguez del Padrón, Diego de Valera y Álvaro de Luna $^{50}$; o las amazonas, incluidas en la obra de Giovanni Boccaccio y mencionadas por Juan Rodríguez del Padrón y Álvaro de Luna ${ }^{51}$. Pero Cartagena señala a estas mujeres guerreras no para que sirvan de modelo, sino como ejemplo de lo que las mujeres no deben hacer, y sólo admite la posibilidad de que, en caso extremo, las mujeres puedan asumir tareas militares de tipo defensivo ${ }^{52}$, tal y como hará más tarde Álvaro de Luna ${ }^{53}$. Además, Alonso de Cartagena también rechaza la inversión de roles: "Pues al igual que se considera vergonzante por demás que los hombres se ocupen del huso y de las labores femeninas, así también es indecoroso para las féminas blandir las lanzas" 54 . Por tanto, a los hombres les corresponderían las funciones que forman parte del ámbito público, mientras que las mujeres quedarían relegadas al ámbito doméstico, idea que también vamos a encontrar en su sobrina Teresa de Cartagena ${ }^{55}$.

\footnotetext{
45 Duodenarium, IV, 23, p. 459.

46 Duodenarium, IV, 17, p. 443.

47 Rodríguez del Padrón, Obras Completas..., pp. 230 y 234. De Luna, Virtuosas..., pp. $229-233$ (Judith), 233-235 (Esther), 235-238 (Débora), 238-240 (la reina de Saba), 345-346 (Pentesilea, reina de las amazonas) y 380-381 (la reina Zenobia), que suponen una selección de ejemplos de mujeres gobernantes. Boccaccio, Mujeres preclaras..., p. 105. Sobre la visión de Rodríguez del Padrón y Valera acerca de la adopción de roles masculinos por parte de las mujeres véase Pelaz Flores, "«A la más virtuosa... »", p. 342. Sobre la visión de la mujer guerrera en Juan Rodríguez del Padrón véase SERrano, “Del debate...”, p. 102. Sobre el interés de Álvaro de Luna por las cualidades de las mujeres en la esfera pública véase FouRnÈs, "De la traduction au manifeste politique: le Libro de las virtuosas e claras mugeres d'Álvaro de Luna", p. 106.

48 Duodenarium, IV, 15, p. 437.

49 Duodenarium, IV, 2, p. 391; 23, pp. 459, 461 у 463.

50 Rodríguez del Padrón, Obras Completas..., pp. 222 y 236. de Valera, Defensa..., pp. 237 y 280. DE LunA, Virtuosas..., pp. 233-235.

51 Boccaccio, Mujeres preclaras..., pp. 93-95 y 154-156. Rodríguez del Padrón, Obras Completas..., pp. 233-234. de LunA, Virtuosas..., pp. 345-346 (Pentesilea) y 366 (Herquia y Antíope).

52 Duodenarium, IV, 23, pp. 459 y 463.

53 DE LunA, Virtuosas..., p. 283.

54 Duodenarium, IV, 23, p. 463.

55 DE CARTagena, Arboleda..., pp. 117-118. Sobre el reparto de funciones entre hombres y mujeres en Teresa de Cartagena véase Cortés Timoner, “«Fue levado...»”, pp. 155 y 158.
} 
Como ejemplo ilustrativo de esta opinión cabe señalar la contraposición que realiza Alonso de Cartagena entre Lucrecia y Catón el Joven: mientras ella permanecía encerrada en casa dedicada al trabajo de la lana, él emprendía acciones bélicas ${ }^{56}$.

También se debate en el marco de la Querella acerca de la educación de las mujeres y su capacidad intelectual, y Cartagena aborda este tema en diferentes secciones del Duodenarium. A este respecto dice en el capítulo 10 de la segunda cuestión que

"En última instancia, sería difícil y casi imposible que todo el pueblo y las propias mujeres, que son consideradas la mitad de la población humana, se familiarizasen con los rudimentos gramaticales, pues habría que construir casi infinitas escuelas y apartar al pueblo la mayor parte del tiempo de sus labores rústicas y de otros menesteres que son útiles a la república"57.

Las mujeres son asemejadas al pueblo llano, y ello evidencia que, en su caso, la clase social era algo completamente indiferente: todas estaban equiparadas al estrato más bajo ${ }^{58}$. Cuestiona que uno y otras puedan aprender gramática, que en la Edad Media constituía la base del sistema educativo, por lo que, en consecuencia, les niega la posibilidad de acceder al conocimiento, entendido como saber institucionalizado ${ }^{59}$. Para él, así pues, la educación sólo puede estar al alcance de una élite masculina ${ }^{60}$. Y niega a las mujeres el derecho a acceder a la educación, pues no concibe que las mujeres puedan realizar otro tipo de tareas más allá de las que tienen asignadas en el ámbito doméstico. Esto contrasta con la actividad literaria desplegada por su propia sobrina, Teresa de Cartagena, que en una de sus obras, Admiraçión operum Dey, se quejaba de que hubiera quien se asombrara de las mujeres que escribían tratados y aprendían las ciencias ${ }^{61}$.

Pero además, Alonso de Cartagena profundiza en sus ideas acerca de la educación y de la capacidad intelectual de las mujeres en diversos capítulos de la cuarta cuestión. Así,

\footnotetext{
56 Duodenarium, IV, 5, p. 401; 6, p. 405.

7 Duodenarium, II, 10, p. 247.

58 Sobre la concepción que Alonso de Cartagena tenía acerca de la sociedad y del papel de cada estamento véase Castilla Urbano, "La función de la metáfora organicista en la obra de Alonso de Cartagena", pp. 85-87.

59 Sobre la diferencia entre saber y conocimiento y la vinculación de este último con el saber institucionalizado véase VARGAS MarTínez, La Querella ..., pp. 268-269.

60 Tal y como ha señalado Francisco Castilla Urbano, "su pretensión [la de Alonso de Cartagena] fue siempre la de contribuir con su saber a la educación de quienes le rodeaban, las clases nobles y los príncipes o monarcas $(\ldots)$ con los que se relacionó durante toda su vida, pero también futuros intelectuales $(\ldots)$ " (Castilla Urbano, "Patriotismo y legitimación monárquica en el pensamiento de Alonso de Cartagena: los escritos de Basilea", p. 141). Y recelaba del acceso a la cultura por parte de los legos, pues eso pondría en peligro el orden social establecido (Fernández Gallardo, Alonso de Cartagena. Una biografia ..., p. 384). ${ }_{61}$ De CARTAgena, Arboleda..., p. 115. A este respecto señala M. ${ }^{a}$ Mar Cortés Timoner que "esta obra destaca en el panorama de la prosa española del 1400 por ser el primer texto escrito por una autora que aparece en defensa de la capacidad intelectual de la mujer y, además, se dirige explicitamente (sic) a otra mujer como respuesta a su solicitud” (CORTÉs Timoner, “«Fue levado...»”, p. 153).
} 
en el capítulo 1 señala que la naturaleza ha dotado a las mujeres de una inteligencia más débil que la de los hombres ${ }^{62}$, opinión que comparte con Diego de Valera ${ }^{63}$. En el capítulo 8, por boca de Lucrecia, expone que la discusión científica debe estar en manos de los varones, correspondiendo a los hombres explicar la teoría y a las mujeres, "a quienes la debilidad de nuestro sexo ha negado escrutar las excelsas ciencias, ponerlas en práctica" ${ }^{94}$. Y en el capítulo 25 prohíbe a las mujeres el acceso al conocimiento teórico y sólo les permite una educación moral a través de los sermones de los predicadores ${ }^{65}$. Con respecto a este tema señalan Luis Fernández Gallardo y Teresa Jiménez Calvente que se muestra más conservador que Leonardo Bruni pero cercano a Juan Luis Vives ${ }^{66}$. Aunque este último autor menciona específicamente que las mujeres deben dedicar unas horas al día a la lectura de obras provechosas ${ }^{67}$, aspecto al que no se refiere ni se puede referir Alonso de Cartagena en el Duodenarium después de haber negado a las mujeres el acceso al conocimiento de la gramática. Y se aleja, desde luego, de las opiniones en este sentido de Giovanni Boccaccio, quien afirmaba que las mujeres no sólo debían dedicarse al cuidado del marido y de los hijos, sino también al estudio, además de presentar un elenco de mujeres inventoras y sabias ${ }^{68}$. También difiere de otros autores hispánicos, como Juan Rodríguez del Padrón, quien denunciaba que las mujeres no tenían mayores conocimientos porque los hombres les impedían el acceso a los estudios; Álvaro de Luna, que reconocerá la capacidad intelectual femenina, así como su papel en la vida política, además de incluir un catálogo de mujeres sabias; y también su sobrina Teresa de Cartagena, que igualmente defendió la capacidad intelectual de las mujeres ${ }^{69}$.

\footnotetext{
62 Duodenarium, IV, 1, p. 385.

63 Diego de Valera atribuye a las mujeres "ingenio perezoso" (DE VALERA, Defensa ..., p. 240).

64 Duodenarium, IV, 8, p. 411.

65 Duodenarium, IV, 25, p. 472.

66 Fernández Gallardo y Jiménez Calvente, El Duodenarium ..., p. 92. Muy similar se muestra Bonilla Cerezo, "Los monarcas del converso. Comentario bibliográfico", p. 39. Respecto a la visión de Leonardo Bruni acerca de la educación de las mujeres véase también Allen, The Concept of Woman. Volume II: The Early Humanist Reformation, 1250-1500, pp. 690-703.

67 Citado por Vargas Martínez, La Querella..., p. 118.

68 Boccaccio, Mujeres preclaras..., p. 313. Entre las mujeres inventoras y sabias señala a Minerva (p. 81), Isis (p. 87), Nicóstrata (pp. 137-139), Nicaula (p. 192), Safo (p. 201), Leoncia (p. 240), Sempronia (p. 294), Hortensia (pp. 307-308), Cornificia (pp. 312-313), Proba (pp. 351-353), Zenobia (p. 364) y la papisa Juana (p. 367).

69 "E si algunas caresçen de las ciencias, esto es por enbidia que los onbres ovieron de su grand sutileza; por el su presto consejo et responder en proviso, non solamente el estudio de las liberales artes, mas de todas las ciencias, les defendiendo" (Rodríguez del PAdrón, Obras Completas..., p. 230). Véanse mujeres sabias en DE LunA, Virtuosas..., pp. 229-233 (Judith), 233-235 (Ester), 238-240 (la reina de Sabba), 241 (Séfora y Fuá), 244-245 (la profetisa Oldra), 249-252 (Abigail, Teanites, Betsabé y Sunamites), 278-283 (Venturia y Beluma), 284-288 (Tanaquil), 297-298 (Avia), 298-299 (Valeria Romana), 343 (Minerva), $345-346$ (Pantasilea), 346-347 (Ceres), 350 (Nicóstrata), 370-371 (Tamaris), 371-372 (Penélope), 375 (Cornificia), $380-381$ (Zenobia), 382 (Erutea), 383-384 (Almatea), 389-391 (Santa Inés) y 433-438 (Catalina). DE CARTAGENA, Arboleda..., p. 115.
} 
Finalmente, Alonso de Cartagena desarrolla la visión del matrimonio que anteriormente había anunciado en dos de los diálogos. Así, en el mantenido entre José y Susana había abordado la cuestión del consentimiento: como hombre de Iglesia, no puede aceptar el matrimonio celebrado sin la aprobación de los cónyuges, incluida la mujer, pero la supedita a la autoridad paterna ${ }^{70}$, por lo que acaba sancionando el modelo de matrimonio que, según Georges Duby, se había impuesto en Europa a partir del siglo XIII, y que aunaba la visión altomedieval del matrimonio como un contrato acordado por los cabezas de familia y la consideración del matrimonio como un sacramento consentido por los contrayentes tal y como pretendía la Iglesia ${ }^{71}$. Por otro lado, en el diálogo entre Fernando III y su madre Berenguela se había referido al control de la sexualidad femenina, al insistir en la necesidad de que la mujer llegue virgen al matrimonio, evite las relaciones sexuales fuera del mismo y renuncie a un segundo matrimonio ${ }^{72}$, una posibilidad que ya había sido criticada por Giovanni Boccaccio y que también rechazará Álvaro de Luna ${ }^{73}$. Pero los últimos capítulos de la cuarta cuestión del Duodenarium constituyen un verdadero manual de la perfecta casada que se anticipa al De Institutione feminae christianae de Juan Luis Vives o a La perfecta casada de fray Luis de León, y que, según Enrique Cantera Montenegro, se inspiran en un poema bíblico, "La mujer fuerte", que aparece en el Libro de los Proverbios (31: 10-31) ${ }^{74}$.

Cartagena se ocupa, por un lado, de las virtudes (fortaleza, pudicia conyugal y fidelidad) propias de la mujer casada ${ }^{75}$, que está obligada a velar por el honor del marido ${ }^{76}$; y por otro lado, de las actividades que debe realizar a fin de no permanecer ociosa ${ }^{77}$. Sería función de la mujer casada practicar obras de caridad con los pobres, atender a las necesidades de su familia y criados, y cuidar de su propia persona: vestirse elegantemente y con decoro, pero sin usar afeites o engaños, cuidar de la limpieza de su cuerpo, pero también de su mente ${ }^{78}$; así pues, no critica el adorno femenino, al igual que Juan Rodríguez del Padrón o Álvaro de Luna, pero sí el uso de artificios, como había hecho previamente Giovanni Boccaccio y haría más tarde el mismo Álvaro de Luna $^{79}$. Pero las tareas de la mujer casada deben consistir, sobre todo, en dirigir la casa

\footnotetext{
Duodenarium, IV, 12, pp. 421 y 423.

DuBy, El caballero, la mujer y el cura, pp. 240-242.

2 Duodenarium, IV, 15, pp. 433 y 435.

73 Boccaccio, Mujeres preclaras..., pp. 14-16, 84-85, 188-189, 249 y 344. DE Luna, Virtuosas..., p. 296 (al hablar de Marcia).

74 Cantera Montenegro, "La mujer judía en la España medieval", p. 40. También se refieren a esta cuestión Fernández Gallardo, La obra literaria ..., pp. 217-218 y 223. Jiménez Calvente, “Alonso de Cartagena...”, p. 149.

75 Duodenarium, IV, 20, pp. 451, 453 y 457. En este caso, la fortaleza debe ser identificada con valía, valor o mérito, según Fernández Gallardo y Jiménez Calvente, El Duodenarium ..., p. 512, nota 143.

76 Duodenarium, IV, 25, p. 471.

77 Duodenarium, IV, 26, p. 475.

78 Duodenarium, IV, 24, pp. 465 y 467; 26, p. 479.

79 Boccaccio, Mujeres preclaras..., p. 261. Rodríguez del Padrón, Obras Completas..., pp. 223-224. DE LunA, Virtuosas..., pp. 319-320. Sobre la relación entre belleza honesta y virtud durante la Edad Media véase VéLEZ-SAINZ, La defensa ..., pp. 105-107.
} 
y ocuparse de las tareas domésticas, incluyendo el trabajo de la lana y el lino ${ }^{80}$. Todas ellas son labores circunscritas al ámbito doméstico, pues la mujer casada debe mostrarse en público lo menos posible, y hasta limitar sus actividades religiosas:

"Pues dedicarse de continuo a oír las predicaciones, frecuentar los altares y encaminarse a los diferentes santuarios peregrinando con frecuencia, mientras descuida su casa, no es recomendable para las mujeres casadas, porque eso parece propio de las viejas vagabundas, no de amas de casa prudentes y devotas" $"$.

Y es que Alonso de Cartagena considera que "los negocios fuera de casa son convenientes para los hombres, no para las mujeres casadas" $"$, lo cual no le impide admitir que las amas de casa provean de lo necesario al personal de servicio y que, en caso de disponer de patrimonio privado, puedan realizar gestiones para aumentarlo, como comprar y plantar ${ }^{83}$, lo cual implica que la reclusión en el ámbito doméstico no podía ser tan estricta como pretendía.

Finalmente, Alonso de Cartagena concluye su breve manual para la mujer casada señalando que "sólo le pedimos que sea devota con Dios, pía con los pobres, guardiana acérrima de su castidad y diligente rectora de los asuntos familiares" $"$, frase que viene a resumir su pensamiento.

\section{La cuarta cuestión con relación a otras obras de la Querella}

La respuesta a la cuarta cuestión del Duodenarium aparece formulada en latín, a diferencia de lo que, según Ana Vargas Martínez, fue habitual entre las autoras y los autores que participaron en la Querella de las mujeres, que prefirieron el uso de la lengua vernácula, lo que facilitaría la difusión de las obras ${ }^{85}$. Pero también es cierto que Alonso de Cartagena no fue un caso único, pues hubo otros escritores y escritoras que usaron la lengua clásica a la hora de participar en el debate, como ejemplifican $D e$ mulieribus claris (1361-c. 1375) de Giovanni Boccaccio, De studiis et litteris (1424) de Leonardo Bruni ${ }^{86}$, De paro aut impari Eva atque Adae peccato (1451) de Isotta Nogarola $^{87}$ o De institutione feminae christianae (1523) de Juan Luis Vives ${ }^{88}$. Aunque

\footnotetext{
Duodenarium, IV, 20, p. 453.

Duodenarium, IV, 26, p. 475.

Duodenarium, IV, 20, p. 455.

Duodenarium, IV, 20, p. 457.

Duodenarium, IV, 26, p. 481.

Vargas Martínez, La Querella..., pp. 23 y 28.

Allen, The Concept of Woman..., vol. 2, p. 690.

7 KING, "Issota Nogarola, humanista y devota (1418-1488)", pp. 35-64.

88 Véanse más ejemplos a este respecto en ArCHER, Misoginia ..., pp. 91-125.
} 
es evidente que, al escoger la lengua latina, Cartagena sin duda dificultó la transmisión de su posicionamiento en la Querella, ya que era una lengua de difícil acceso para los laicos $^{89}$, y muy especialmente por lo que se refiere a las mujeres ${ }^{90}$. Pero no debemos olvidar que él mismo le propuso a Fernán Pérez de Guzmán traducirla al castellano ${ }^{91}$, lo cual nos hace suponer que era consciente del problema, pues habitualmente "concebía las traducciones como una forma de divulgar el saber entre quienes desconocían el latín, la única forma en que éstos podían tener acceso a los textos clásicos" ${ }^{\prime 92}$. Según Luis Fernández Gallardo, "Cartagena asignó al guerrero, al bellator, el uso de la lengua vernácula y al sacerdote, al orator, el del latín", por lo que no resulta extraño que él mismo considerara necesaria una traducción al castellano del Duodenarium, si bien ésta finalmente no se llevó a cabo.

Todo ello no impidió, sin embargo, que la cuarta cuestión del Duodenarium formara parte de la Querella de las mujeres, a pesar de que, según Luis Fernández Gallardo y Teresa Jiménez Calvente, la obra tuvo una "limitada difusión manuscrita"94. Pero son muchos los rasgos comunes a otras obras habitualmente incluidas en la misma, más allá de los temas abordados y que hemos señalado en el apartado anterior.

Por un lado, tanto Alonso de Cartagena en la cuarta cuestión del Duodenarium como Juan Rodríguez del Padrón en el Triunfo de las donas pretenden responder a una pregunta muy similar: "la questión odiosa ¿qual sea, la muger o el hombre, más noble e de más exçelencia?" "95, por lo que se refiere a Rodríguez del Padrón; “¿quién debe ser considerado más admirable, más loable y mejor: un hombre óptimo o una mujer óptima?", en el caso de Cartagena. También encontramos en ambos la presentación de parejas masculinas y femeninas, si bien Alonso de Cartagena lo hace con la intención de equipararlos en virtudes (pero que, en la práctica, como ya hemos dicho, acaba reflejando la superioridad de los hombres sobre las mujeres), mientras que en Juan Rodríguez del Padrón el objetivo al mencionar sucesivas parejas es contrastar las virtudes femeninas

\footnotetext{
89 Alvar, "Boccaccio en Castilla: entre recepción y traducción”, p. 333. Fernández Gallardo, "Autotraducción y literatura devocional: la Apología sobre el salmo "Iudica me, Deus" de Alonso de Cartagena", p. 577.

90 Véase una reflexión a este respecto en Ríos DE LA LLAVE, "Porque aunque a las mujeres les está proybido el predicar, no les está proybido aprender y leer y hablar en cosas de Dios, particularmente entre sí: La instrucción cristiana de las mujeres conversas en los siglos XV y XVI”, pp. 179-193.

91 Duodenarium, ultílogo del primer binario, p. 265.

92 Morrás Ruiz-Falcó, "El debate entre Leonardo Bruni y Alonso de Cartagena: las razones de una polémica”, p. 46. Igualmente se preocupó Alonso de Cartagena de que la instrucción religiosa que recibían los fieles de su diócesis fuera eficaz, y para ello ordenó componer un cuaderno que incluyera los artículos de fe, los sacramentos, los mandamientos, las virtudes cardinales y teologales, los pecados mortales y las obras de misericordia en lengua vernácula, y del que debía haber un ejemplar en cada iglesia parroquial para que el cura se encargara de leerlo en la misa de ciertos domingos y días festivos (Fernández Gallardo, Alonso de Cartagena. Una biografia..., p. 258).

93 Fernández Gallardo, “Autotraducción...”, p. 576.

94 Fernández Gallardo y Jiménez Calvente, El Duodenarium..., p. 133. También en Jiménez Calvente, “Alonso de Cartagena...", p. 149.

95 Rodríguez del PAdrón, Obras Completas..., p. 213.
} 
con los vicios masculinos ${ }^{96}$. Y finalmente, la justificación de la preeminencia de la reina María sobre la emperatriz de Alemania y sobre la reina francesa que hace Rodríguez del Padrón al final del Triunfo de las donas ${ }^{97}$ parece remitir al discurso sobre la preeminencia de España sobre Inglaterra que Cartagena pronunció el 14 de septiembre de 1434 en el marco del Concilio de Basilea, al que es muy probable que acudiera Rodríguez del Padrón en calidad de criado del cardenal Juan de Cervantes ${ }^{98}$.

Por otro lado, se detectan semejanzas entre la cuarta cuestión del Duodenarium y la Defensa de virtuosas mujeres de Diego de Valera ${ }^{99}$. Ambos autores manifiestan de forma expresa su deseo de responder a los autores misóginos: "aquestos comendadores de nueva seta, que rotamente les plaze en general de todas las mugeres maldezir" ${ }^{100} \mathrm{o}$ "las tales venenosas lenguas" 101 y "maldicientes blasfemadores"102 en el caso de Valera, y que, según Robert Archer, ya figuraría en la refutación de los maldients realizada por Francesc Eiximenis en el Libre de les dones ${ }^{103}$, mientras que Cartagena estaría actuando contra "aquellos que con boca de perro intentan hablar mal de las mujeres". Además, ambas obras están escritas en forma de carta dirigida a un amigo. A esto cabría añadir el interés por mujeres más próximas en el espacio y el tiempo que los ejemplos tradicionales en otros tratados, aunque no sean estrictamente mujeres contemporáneas a los autores, como son la reina Berenguela en el caso de Alonso de Cartagena, y María Coronel, la madre de Álvar Pérez de Osorio (María Fernández de Villalobos) y María García la Beata, en el caso de Diego de Valera ${ }^{104}$.

Finalmente, y tal y como Luis Fernández Gallardo y Teresa Jiménez Calvente han puesto de manifiesto, el Duodenarium influyó sobre el Libro de las virtuosas e claras mujeres de Álvaro de Luna ${ }^{105}$. También este último autor quiere rebatir a "aquellos que siniestras cosas contra ellas non se avergüenzan nin dubdan de dezir" ${ }^{106}$, y compara a las mujeres

\footnotetext{
96 Rodríguez del Padrón, Obras Completas..., pp. 233-237, 242 y 247.

97 Rodríguez del Padrón, Obras Completas..., pp. 253-254. Sobre la relevancia política de este aspecto véase SERRANo, "La cuestión...", pp. 1.677-1.678.

98 Rodríguez del Padrón, Obras Completas..., pp. 11 y 14. Sobre el discurso de Alonso de Cartagena acerca de la preeminencia de Castilla sobre Inglaterra véase Fernández Gallardo, Alonso de Cartagena. Una biografia ..., pp. 142-160. También Castilla Urbano, "Patriotismo...", pp. 145-150.

99 Federica Accorsi ha señalado que Diego de Valera conocía al menos dos obras de Alonso de Cartagena, la Copilación de algunos dichos de Séneca y las Epistolae morales ad Lucilium, y piensa que pudo inspirarse en la defensa de las mujeres hecha por Alonso de Cartagena (DE VALERA, Defensa..., pp. 81, 182 y 192). También apunta la influencia de las glosas de Cartagena acerca de "la cuestión femenina" en Valera en ACCORsi, "La influencia...", pp. 17, 20 y 22.

100 de Valera, Defensa..., p. 230.

101 de Valera, Defensa..., p. 240.

102 de Valera, Defensa..., p. 249.

103 Archer, The Problem..., p. 125.

104 DE VAlera, Defensa..., pp. 229 y 243.

105 Fernández Gallardo y Jiménez Calvente, El Duodenarium..., p. 90. Jiménez Calvente, “Alonso de Cartagena...", p. 142.

106 DE LunA, Virtuosas..., p. 213.
} 
ilustres que cita con ciertos hombres ${ }^{107}$, lo que remite a las parejas de la cuarta cuestión del Duodenarium, y que ya dijimos que también se encuentra en la obra de Juan Rodríguez del Padrón. Además, mientras que en los diálogos del Duodenarium se suceden una pareja pagana, una pareja judía y una pareja cristiana, ejemplos que Cartagena ha buscado en la Ley de la Escritura y la Ley de la Naturaleza, Álvaro de Luna incluye un catálogo de mujeres virtuosas judías, paganas y cristianas, agrupadas en tres libros, que se corresponden con la ley divinal de la escritura, la ley de natura y la ley de gracia $^{108}$. En este sentido tanto Alonso de Cartagena como Álvaro de Luna y también los anteriormente citados Juan Rodríguez del Padrón y Diego de Valera estarían siguiendo la estela de Giovanni Boccaccio, que en su De mulieribus claris había presentado un catálogo de mujeres ilustres, aunque en su caso principalmente de origen pagano ${ }^{109}$.

\section{La valoración del pensamiento de Alonso de Cartagena en el marco de la Querella}

Los hombres y mujeres que optaron por defender a las mujeres en el marco de la Querella fundamentalmente lo hicieron elaborando catálogos de mujeres ilustres que habían destacado en el pasado, como las que aparecen en el De mulieribus claris de Giovanni Boccaccio, que incluye una relación de heroínas célebres por su virtud, coraje, saber, capacidades políticas, intelectuales y guerreras ${ }^{110}$. Aunque también los detractores de las mujeres elaboraron listas de mujeres a las que achacaban todos los vicios y culpaban de todos los males ${ }^{111}$.

Por la cuarta cuestión del Duodenarium desfila un pequeño grupo de mujeres ilustres (la Virgen María, Ester, Lucrecia, Susana, Berenguela de Castilla, las amazonas, las mujeres vizcaínas, Juana de Arco), demasiado breve como para llegar a una conclusión sobre el posicionamiento de su autor, y que guarda relación con su insistencia en ser neutral, en

107 En la obra de Álvaro de Luna se pueden encontrar ejemplos de mujeres del Antiguo Testamento que son comparadas con hombres paganos, o con hombres del Antiguo Testamento, o con los apóstoles y mártires cristianos, así como a mujeres gentiles que son cotejadas con paganos, o con hombres del Antiguo Testamento, o con hombres del Nuevo Testamento y cristianos, y finalmente a algunas mujeres cristianas que son confrontadas con hombres paganos o con hombres cristianos. Los ejemplos más numerosos se refieren a la comparación entre mujeres del Antiguo Testamento y hombres paganos, mujeres gentiles y hombres paganos, y mujeres gentiles y hombres del Antiguo Testamento.

108 Sobre la procedencia de las biografías de mujeres santas que figuran en la obra de Álvaro de Luna véase Hernández Amez, "Mujer...”, pp. 255-288, especialmente pp. 268-277. Sobre la relación de la división tripartita utilizada por Álvaro de Luna con el tema de los nueve caballeros de la fama (tres paganos, tres cristianos y tres judíos), igualmente presente, en su variante femenina, en diversas obras relacionadas con la Querella de las mujeres, véase Fournès, "De la traduction...", pp. 104-105.

109 DE Luna, Virtuosas..., p. 209. Boccaccio, Mujeres preclaras..., p. 61. Sobre la utilización de la obra de Boccaccio por Álvaro de Luna véase McGovern, "Writing...”, pp. 330-334.

110 Las biografías de mujeres no eran un género nuevo, puesto que había sido inaugurado por Plutarco con sus Mulierum virtutes, y continuado por Ovidio en las Heroidas y la Metamorfosis. Igualmente lo había practicado San Jerónimo en su Epístola Ad Principam, donde recoge la vida de diecinueve mujeres virtuosas (Niccoli (ed.), La mujer del Renacimiento, p. 14. DE LunA, Virtuosas..., pp. 50 y 58-59).

111 Vargas Martínez, La Querella..., p. 186. 
no mostrarse a favor de los hombres ni a favor de las mujeres: "Yo, por mi parte, para satisfacer tu deseo, no quiero complacerte hasta el punto de elegir y anteponer, según mi criterio, un hombre a una mujer o una mujer a un hombre (...)"112. Una falta de determinación que, quizás, venga inspirada por el hecho de que, en su opinión, hay aspectos en los que los hombres superan a las mujeres, y otros en los que ocurre todo lo contrario ${ }^{113}$. Por otro lado, y a pesar de su pretendida neutralidad, Alonso de Cartagena quiere responder a los autores misóginos ${ }^{114}$. Pero al mismo tiempo presenta sus argumentos a través de sucesivas parejas de hombres y mujeres que se dedican a alabar al sexo contrario; y como, "para que atribuyamos al rubor femenino, como corresponde, una respuesta honesta antes que una primera alocución" 115 y con la excusa de que "el recato femenino no les permite hablar a ellas en primer lugar ni siquiera entre los suyos" "116, siempre es un hombre el primero en hablar, y una mujer la última en responder, para concluir que las virtudes del hombre son superiores a las de ella ${ }^{117}$, por lo que la idea que perdura en el lector es la de la superioridad del hombre sobre la mujer. A lo cual cabe añadir, tal y como ha señalado Luis Fernández Gallardo, que su modelo de mujer ideal se corresponde con el de "la matrona que alcanzaba la excelencia propia de su sexo en la labor cotidiana"118. Así pues, ¿podemos incluir a Alonso de Cartagena entre los hombres que defendieron a las mujeres o debe ser incorporado al catálogo de autores misóginos?

Algunos investigadores han puesto de manifiesto que no existen diferencias marcadas entre los autores que escriben en contra de las mujeres y los que escriben a favor, esto es, que los autores que defienden a las mujeres también utilizan argumentos patriarcales tradicionales, de tal manera que contribuyen a prolongar la posición de subordinación de las mujeres ${ }^{119}$. Tal y como ha destacado Marion Coderch, la distinción entre misoginia y defensa resulta insuficiente, máxime si tenemos en cuenta que hubo autores que escribieron tanto a favor como en contra de las mujeres ${ }^{120}$. Fue el caso de Giovanni Boccaccio, que atacó a las mujeres en Il Corbaccio (c. 1355) y las defendió en De mulieribus claris (1361-c. 1375) ${ }^{121}$. También Jehan Le Fèvre, quien a

\footnotetext{
${ }_{112}$ Duodenarium, IV, 2, p. 389. La misma idea en Duodenarium, IV, 4, p. 397.

113 Duodenarium, IV, 3, p. 391; 19, p. 447.

114 Duodenarium, IV, 3, p. 391.

115 Duodenarium, IV, 5, p. 401.

116 Duodenarium, IV, 15, p. 433.

117 También lo señala Jiménez Calvente, “Alonso de Cartagena...”, pp. 143 y 147.

118 Fernández Gallardo, La obra literaria..., p. 222.

119 Walthaus, “"Gender», Revalorización y Marginalización: la Defensa de la Mujer en el Siglo XV”, pp. 273-274. van Veen, "La mujer en algunas defensas del siglo XV: Diego de Valera y Juan Rodríguez del Padrón y los mecanismos de género”, pp. 465-466 y 471-472.

${ }^{120}$ CoDERCH, “«Escapando de la molicie mujeril»: Virtudes femeninas y atributos de género en los tratados de defensa de las mujeres (siglos XIV y XV)", pp. 75-77. Parece ser que el empleo de argumentos misóginos y en defensa de las mujeres es una técnica literaria habitual entre finales del siglo XIII y finales del siglo XV (Archer, Misoginia ..., p. 224).

121 VÉlez-SAINZ, La defensa..., p. 140. Aunque algunas autoras señalan que esa dualidad (apoyo y rechazo de las mujeres) está presente al mismo tiempo en De mulieribus claris (PRATT, "The strains of defense: the many voices of Jean Lefèvres Livre de Leesce”, p. 120. BENSON, “Debate...”, p. 183).
} 
finales del siglo XIV presentó argumentos contra las mujeres en su traducción de Les Lamentations de Matheolus y luego los rebatió en Le Livre de Leesce ${ }^{122}$. Igualmente Leonardo Bruni, que habló a favor de las mujeres en De studiis et litteris (1424), pero no dudó en desaconsejar el estudio de la retórica en la instrucción femenina, pues, en su opinión, las mujeres no debían participar en la vida pública ${ }^{123}$. De forma similar actuó Pere Torroella, que primero denigró a las mujeres en las Coplas de las calidades de las donas (o maldezir de mugeres) (c. 1458), pero luego se retractó en Razonamiento en defensión de las donas (1458-1462) ${ }^{124}$. Y también Antón Montoro, que atacó a las mujeres en las Coplas del provincial, pero las defendió en Yo sé quién sois, Torrellas ${ }^{125}$. Probablemente todos ellos siguieran el ejemplo de Ovidio, que habló bien de las mujeres en la Metamorfosis, pero las criticó en el Arte de amar $^{126}$. Y lo que sí parece evidente es que este desdoblamiento está presente en la cuarta cuestión del Duodenarium, algo poco extraño si tenemos en cuenta que Alonso de Cartagena fue amigo de uno de estos autores, Leonardo Bruni, con el que polemizó entre 1436 y 1439 sobre la forma en que debía traducirse a Aristóteles del griego al latín ${ }^{127}$. Una dualidad que, por otro lado, guarda relación con el método de trabajo seguido en las universidades medievales, el método escolástico, consistente en abordar las cuestiones objeto de debate ofreciendo argumentos a favor y en contra antes de llegar a la sententia del autor ${ }^{128}$, si bien en el caso de Alonso de Cartagena esta última no está tan clara, pues elude pronunciarse a favor o en contra de las mujeres o de los hombres.

Para tratar de posicionar a Alonso de Cartagena hemos optado por utilizar como método de análisis la teoría desarrollada por Prudence Allen para explicar el concepto de mujer

122 Pratt, "The strains...", pp. 113-114. Aunque la autora concluye en la p. 128 que Le Livre de Leesce resulta ambiguo. LouZADA FonseCA, "Difamación y defensa de la mujer en la Edad Media. Pasajes obligatorios", p. 88.

123 Allen, The Concept of Woman..., vol. 2, p. 698.

124 Archer, Misoginia ..., pp. 47-48. Vargas Martínez, La Querella ..., p. 116.

125 DE Luna, Virtuosas..., p. 38.

126 Vargas Martínez, La Querella..., p. 225. Sobre la visión acerca de las mujeres en Ovidio véase VéLEZSAINZ, La defensa..., pp. 44-46.

127 di CAmillo, El humanismo..., pp. 129, 147 y 203-226. Aguadé Nieto, Libro y cultura italianos en la Corona de Castilla durante la Edad Media, pp. 153-154. Verdín-DíAz, Alonso de Cartagena y el Defensorium Unitatis Christianae, pp. 82-84. De Cartagena, Doctrinal..., p. XXX. Fernández Gallardo, "En torno a los «studia humanitatis» en la Castilla del Cuatrocientos. Alonso de Cartagena y los autores antiguos", pp. 218-225 y 228-233. González Rolán, Moreno Hernández y Saquero SuÁrez-Somonte, Humanismo y teoría de la traducción en España e Italia en la primera mitad del siglo XV. Edición y estudio de la Controversia Alphonsiana (Alfonso de Cartagena vs. L. Bruni y P. Candido Decembrio), pp. 14, 62 y 82-103. Morrás Ruiz-Falcó, "El debate...", p. 36. Fernández Gallardo, "Alonso de Cartagena y el humanismo", pp. 184188, 190-192 y 194. de Luna, Virtuosas..., p. 30. di CAmillo, "Fifteenth-Century...", pp. 21-23. Fernández Gallardo, La obra literaria ..., pp. 110-111, 161 y 167-175. Fernández Gallardo y Jiménez Calvente, El Duodenarium..., pp. 38 y 40.

128 Este método de argumentación es utilizado a lo largo de toda la obra, según ha hecho notar JIMÉNEZ CALvente, "Alonso de Cartagena...", pp. 136 y 138. Véase resumido el debate sobre la relación de Alonso de Cartagena con el escolasticismo y el humanismo en Morrás Ruzz-Falcó, "El debate...", pp. 37-38. Sobre la relación de la Querella de las mujeres con la disputatio escolástica véase VéLEZ-SAINZ, La defensa ..., pp. 33-36. 
de los principales filósofos y filósofas y de algunos escritores y escritoras del período comprendido entre los presocráticos y el siglo XVI ${ }^{129}$. Según esta investigadora, a lo largo de la historia ha habido varias formas de entender las relaciones de los sexos y las relaciones entre los sexos: la teoría de la complementariedad de los sexos, la teoría de la polaridad de los sexos, la teoría de la polaridad inversa de los sexos, la teoría de la unidad de los sexos y la teoría de la neutralidad de los sexos, aunque más recientemente ha sustituido el término "sexo" por el de "género". Y también ha destacado que, mientras el pensamiento de algunos autores y autoras se encuadra en una de estas teorías, en el de otros se pueden ver representadas varias ${ }^{130}$, situación que parece ejemplificar Alonso de Cartagena.

Por un lado, en el Duodenarium se puede ver reflejada la teoría de la polaridad de los sexos, como cuando en el capítulo 19 de la tercera cuestión achaca los defectos del rey Mauregato al hecho de ser "seguidor no de la claridad de su padre, sino de la oscuridad de su madre"131: Cartagena otorga un valor moral al color de la piel (la madre de Mauregato era una esclava musulmana llamada Sisalda) ${ }^{132}$, y lo utiliza para presentar al padre y a la madre como dos polos opuestos, atribuyendo al hombre un valor superior al de la mujer, tal y como es característico en la teoría de la polaridad de los sexos. También cuando insinúa la oposición entre las virtudes propias de los hombres (vigor físico, audacia, fortaleza) y los vicios de las mujeres (blandura, debilidad, imprudencia, mezquindad) $)^{133}$. O igualmente al diferenciar la educación de las mujeres de la de los hombres ${ }^{134}$. Pero, aunque Aristóteles, al que Prudence Allen considera el primer exponente de esta teoría ${ }^{135}$, inspira el pensamiento político de Alonso de Cartagena ${ }^{136}$ y algunas de sus obras están presentes en el Duodenarium, especialmente la Ética a Nicómaco y la Política ${ }^{137}$, Alonso de Cartagena nunca llega a afirmar que las mujeres son opuestas a los hombres, ni que los hombres son superiores a las mujeres, sino que insiste en que en unos casos los hombres son superiores, y en otros las mujeres ${ }^{138}$.

En alguna ocasión Alonso de Cartagena apunta hacia la teoría de la polaridad inversa, aquella que da más valor a las mujeres que a los hombres, como cuando concluye, tras comparar a la Virgen María con Juan el Bautista, el más santo de los hombres, que "una mujer optima (sic) vale más que un varón óptimo"139. Si bien esta teoría es más

\footnotetext{
129 Allen, The Concept of Woman. The Aristotelian Revolution, 750 B.C. - A.D. 1250, vol. 1.

130 Allen, The Concept of Woman ..., vol. 1, pp. XXI, 2-3 y 6.

${ }_{131}$ Duodenarium, III, 19, p. 347.

132 Fernández Gallardo y Jiménez Calvente, El Duodenarium ..., p. 507, nota 105.

133 Duodenarium, IV, 2, p. 391; 4, p. 397.

134 Duodenarium, II, 10, p. 247 y IV, 25, p. 472.

135 Prudence Allen señala que la difusión en el siglo XIII del concepto de mujer presente en las obras de Aristóteles provocó un desarrollo de la teoría de la polaridad de los sexos, fenómeno al que ella aplica la denominación de revolución aristotélica (AlLen, The Concept of Woman ..., vol. 1, pp. 1, 4, 7, 251-252 y 413-414).

${ }^{136}$ Fernández Gallardo, Alonso de Cartagena. Una biografía..., pp. 321 y 332.

137 Fernández Gallardo y Jiménez Calvente, El Duodenarium..., pp. 40, 89 (nota 111) y 109.

${ }_{138}$ Duodenarium, IV, 3, p. 391; 19, p. 447.

139 Duodenarium, IV, 1, p. 387.
} 
habitual a partir del siglo XVI, la opinión de Cartagena no supone algo excepcional en el período medieval, pues Prudence Allen ha apuntado a que se encuentra presente en la defensa que hizo Pedro Abelardo de la superioridad de las mujeres sobre los hombres en el tema de la gracia, o incluso en la visión de la mujer dentro del amor cortés ${ }^{140}$. En el ámbito hispánico, por ejemplo, también la vemos reflejada en Juan Rodríguez del Padrón, que ofrece cincuenta razones para justificar la excelencia de las mujeres por encima de los hombres ${ }^{141}$, o cuando Álvaro de Luna afirma, de ciertas mujeres, que son iguales o superiores a muchos varones ${ }^{142}$. Pero no es la teoría que prevalece, máxime cuando las afirmaciones de Cartagena en este sentido sólo son atribuidas a una mujer en concreto: la Madre de Dios.

La teoría de la complementariedad de los sexos, que es la que predomina a lo largo de la Edad Media entre los defensores de las mujeres, y que está presente en Teresa de Cartagena, cuando señala que Dios no creó diferentes a hombres y mujeres para dar preeminencia a unos sobre otros, sino para prestarse ayuda mutua ${ }^{143}$, también se puede ver reflejada en Alonso de Cartagena. Así, cuando señala que hombres y mujeres tienen una naturaleza diferente, separando sus ámbitos de actuación, puesto que distingue entre virtudes masculinas y virtudes femeninas, y entre funciones masculinas y funciones femeninas, al tiempo que rechaza la inversión de roles $^{144}$. Y ello resulta evidente cuando Alonso de Cartagena ordena que

"Cese, pues, la rivalidad entre los sexos y cada uno de ellos aspire a las insignias de la honestidad que le son propias, pues aunque los actos honorables de la fuerza viril suelen ser más fructíferos, de mayor peso y más útiles para el conjunto de la república, la honestidad femenina es la más hermosa y sus ramas tanto más dignas de admiración cuanto más tierna es la raíz de la que crecen"145.

Finalmente, el pensamiento de Alonso de Cartagena también se encuentra impregnado de la teoría de la unidad de los sexos. Según Prudence Allen, esta última teoría se desarrolla a fines de la Edad Media, en el marco del humanismo, gracias a la difusión del pensamiento de Platón ${ }^{146}$. Y a este respecto conviene tener presente que Alonso de Cartagena le proporcionó al Marqués de Santillana algunas aclaraciones sobre el $D e$

140 Allen, The Concept of Woman ..., vol. 1, pp. 271 y 329.

${ }^{141}$ Rodríguez del Padrón, Obras Completas..., pp. 217-252.

142 DE Luna, Virtuosas..., pp. 227-229 (María, la hermana de Moisés y Aarón), 235-238 (la profetisa Débora), 302-303 (Marcia, hija de Varro), 345-346 (Pantasilea), 346-347 (Ceres), 369 (Camila), 370 (Tamaris), 375 (Cornificia), 378-379 (Mariane), 380-381 (Zenobia), 383-384 (Almatea) y 405-408 (María Egipciana).

143 de Cartagena, Arboleda..., pp. 117-119. Sobre la complementariedad de los sexos en Teresa de Cartagena véase Vélez-Sainz, La defensa ..., pp. 299 y 327-333. Cortés Timoner, “«Fue levado...»”, p. 155.

${ }_{144}$ Duodenarium, IV, 1, p. 385; 2, p. 389; 3, pp. 391 у 395; 4, pp. 395 у 397.

${ }_{145}$ Duodenarium, IV, 19, p. 447; 23, p. 463.

146 Allen, The Concept of Woman ..., vol. 1, p. 6 y vol. 2, p. 689. Sobre la visión acerca de las mujeres en Platón véase Vélez-SaInz, La defensa..., pp. 41-42. 
militia de Leonardo Bruni, donde se revela la influencia del platonismo ${ }^{147}$ y es autor de la primera cita castellana del Fedón, que Leonardo Bruni había traducido al latín en $1426^{148}$. Y, sobre todo, hay que tener en cuenta que Alonso de Cartagena había adquirido en Basilea un ejemplar de la versión latina de la República de Platón realizada hacia 1402 por Uberto Decembrio, según le mencionaba Alonso al hijo de Uberto, Pier Candido Decembrio, con el cual mantuvo una relación epistolar a partir de $1437^{149}$. Además, Alonso de Cartagena se encargó de corregir la traducción de la obra que llevó a cabo el propio Pier Candido Decembrio ${ }^{150}$, e incluyó un análisis comparativo entre Aristóteles y Platón ${ }^{151}$, así como una valoración del tratamiento que este último dio a las mujeres en el quinto libro de la República ${ }^{152}$.

Por tanto, es indudable el conocimiento que Alonso de Cartagena tenía de esta obra de Platón. De hecho, señala Luis Fernández Gallardo que Alonso de Cartagena, que defendió en 1438 ante el emperador alemán la tesis de la conveniencia del gobierno de los filósofos, fue el primer autor hispano en citar la República ${ }^{153}$, aunque también matiza que "las arraigadas convicciones aristotélicas de Cartagena no iban a sufrir merma alguna ante un conocimiento directo de la doctrina platónica"154. Ello no impide, sin embargo, que se manifieste una cierta influencia del pensamiento de Platón acerca de las mujeres en la cuarta cuestión del Duodenarium, y a pesar de existir también diferencias entre ambos ${ }^{155}$.

\footnotetext{
147 Fernández Gallardo y Jiménez Calvente, El Duodenarium..., p. 38.

148 Fernández Gallardo, La obra literaria ..., pp. 138-139.

149 Saquero Suárez-Somonte y GonzÁlez Rolán, "Actitudes renacentistas en Castilla durante el siglo XV: la correspondencia entre Alonso de Cartagena y Pier Cándido Decembrio", pp. 206-209 y cartas VII y VIII en pp. 218-220. Fernández Gallardo, "En torno a los «studia humanitatis»...", pp. 227 y 235. Fernández Gallardo, Alonso de Cartagena. Una biografia..., pp. 182 y 216. Fernández Gallardo, "Alonso de Cartagena y la escritura...", pp. 50-51, 74-75 y 77. Fernández Gallardo, "Las ideas políticas de Alonso de Cartagena", p. 416. Fernández Gallardo, "Alonso de Cartagena y el humanismo"..., pp. 192-193 y 197-198. di Camillo, "Fifteenth-Century...", p. 22, nota 3. Fernández Gallardo, La obra literaria ..., pp. 175-183. Fernández Gallardo y Jiménez Calvente, El Duodenarium ..., p. 41. La traducción latina de La República de Platón hecha por Pier Candido Decembrio ya circulaba por territorio hispánico en 1441 (GoNzález Rolán, Moreno Hernández y Saquero SuÁrez-Somonte, Humanismo..., p. 64). Véase una referencia directa de Alonso de Cartagena a la traducción de Uberto Decembrio en carta VIII, pp. 384-387.

150 González Rolán, Moreno Hernández y Saquero Suárez-Somonte, Humanismo ..., carta I, pp. 354-355; carta II, pp. 356-357; carta VIII, pp. 380-381; y prefacio con la dedicatoria, pp. 436-439.

151 Fernández Gallardo, La obra literaria ..., pp. 181-182. Alonso de Cartagena habría sido "pionero en el intento de establecer una concordancia entre Platón y Aristóteles" (González Rolán, Moreno Hernández y Saquero SuÁrez-Somonte, Humanismo..., p. 139). De hecho, el propio Alonso de Cartagena pone de manifiesto en su correspondencia con Pier Candido Decembrio su intención de conciliar a los dos filósofos (carta VIII, pp. 382-383).

152 di CAMillo, "Fifteenth-Century...", p. 31.

153 Fernández Gallardo, Alonso de Cartagena. Una biografía..., pp. 216 y 346. Fernández Gallardo, La obra literaria..., p. 181

154 Fernández Gallardo, La obra literaria..., p. 182.

${ }_{155}$ Por ejemplo, respecto al tema de la educación de las mujeres, que Alonso de Cartagena limita, frente a la defensa que hace Platón. Sobre el apoyo de este último a la educación femenina véase VélEz-SAINZ, La defensa..., p. 41.
} 
En la obra de Alonso de Cartagena son constantes las menciones de la palabra "república" 156 , y se evidencian las características propias de la teoría de la unidad de los sexos, como cuando Alonso de Cartagena valora a aquellas mujeres que son capaces de llegar al mismo nivel que los hombres (las "mujeres viriles"), o en las ocasiones en que utiliza unas mismas virtudes para comparar a hombres y mujeres, tal y como harán posteriormente Diego de Valera (en alguna ocasión) y principalmente Álvaro de Luna, al señalar que virtudes y pecados son comunes a hombres y mujeres ${ }^{157}$. Este rasgo se pone de manifiesto, principalmente, en los diálogos entre las parejas seleccionadas por Cartagena: equipara a Catón el Joven y a Lucrecia en honestidad, austeridad y rigor, y dice de ella que había asumido, "en el castigo a ti misma, una virtud masculina"158; afirma que José y Susana son iguales en castidad y fortaleza, y resalta de ella que tenía un "corazón viril" 159 , esto es, que se comportaba de la misma manera que un hombre; y alaba en Berenguela su capacidad para gobernar el reino, cuando "ciertamente el oficio de reinar es propio de hombres y no de cualquier tipo de hombres, sino de los hombres más perfectos" ${ }^{160}$. Y dado que, a lo largo de dichos diálogos, la última opinión, la de la mujer, siempre tiende a remarcar la superioridad del hombre con relación a dichas virtudes, podemos concluir que en Alonso de Cartagena el hombre se convierte en medida de lo que debe ser toda la humanidad (hombres y mujeres) y que sólo valora a aquellas mujeres que son capaces de alcanzar el mismo nivel que los hombres en ciertas virtudes y en ciertas funciones, aunque sin contar con las mismas oportunidades para conseguirlo, rasgos propios de la teoría de la unidad de los sexos. Esta idea queda reforzada en la parte final de la cuarta cuestión del Duodenarium, la dedicada al manual de la perfecta casada, cuando su autor insiste en que

"pediré a los maridos, no a las mujeres, fortaleza guerrera o gobierno prudente de las ciudades o justa venganza contra los criminales y consejo maduro en los asuntos públicos o bien las demás cosas de este tipo que son esperables en los corazones masculinos. Mas si estas cualidades residieran en los corazones de algunas féminas, las recibiría con sumo júbilo"161.

\footnotetext{
156 Véase Duodenarium, II, 10, p. 247; III, 4, p. 293; III, 8, p. 307; IV, 3, p. 393; IV, 15, p. 435; IV, 16, p. 437; IV, 17, p. 443; IV, 18, p. 445; IV, 19, p. 447. Según Luis Fernández Gallardo, Alonso de Cartagena utiliza la expresión para hacer referencia al "ámbito en que tienen lugar las relaciones entre los hombres cuya consideración compete a la ciencia política" (Fernández Gallardo, "Las ideas políticas...”, p. 418), y que identifica, por un lado, con la Iglesia, y por otro lado, con el reino.

157 de Valera, Defensa ..., p. 287. de Luna, Virtuosas ..., p. 217. Sobre la matización de la idea de igualdad entre hombres y mujeres en Diego de Valera, véase van VeEn, "La mujer...", pp. 467-468. Sobre la defensa de igualdad entre hombres y mujeres en la obra de Álvaro de Luna véase Hernández Amez, "Mujer...", p. 284. Sobre las virtudes varoniles de las mujeres en Álvaro de Luna véase Fournès, "De la traduction...", p. 106.

${ }_{158}$ Duodenarium, IV, 5, pp. 399 y 401.

${ }_{159}$ Duodenarium, IV, 10, p. 417.

160 Duodenarium, IV, 15, p. 435.

161 Duodenarium, IV, 26, p. 481.
} 


\section{Conclusiones}

A través del análisis de la cuarta cuestión del Duodenarium se evidencia la participación de Alonso de Cartagena en la Querella de las mujeres, en tanto en cuanto pretende rebatir a los autores que critican a las mujeres, no duda en recurrir como ejemplo a diferentes figuras femeninas que suelen ser mencionadas por los autores que participan en la misma y, sobre todo, manifiesta sus opiniones sobre temas que suelen ser tratados habitualmente por quienes toman parte en el debate, como son la naturaleza de las mujeres y sus virtudes; su participación en el gobierno, la justicia y la guerra; las funciones y actividades de las mujeres; su capacidad intelectual y su acceso al conocimiento; el matrimonio y el papel de las mujeres casadas.

Y si bien Alonso de Cartagena se decanta por la superioridad de las virtudes masculinas sobre las femeninas y por limitar la participación de las mujeres en las actividades del ámbito público, que considera propio de los hombres, al tiempo que relega a las mujeres al papel tradicional de subordinación en el ámbito doméstico, alejándolas del estudio y la educación, también es cierto que hay algunos aspectos que impiden posicionarlo entre los detractores de las mujeres, máxime cuando él mismo aspiró a mantener un puesto neutral, y no dudó en destacar que los hombres son superiores en unas cosas y las mujeres en otras, y valoró a las mujeres capaces de actuar en el ámbito público. En definitiva, y tal y como hemos demostrado, sus ideas pueden encuadrarse en las diversas formas de entender las relaciones de los sexos y entre los sexos enunciadas por Prudence Allen. Una indeterminación que no resulta excepcional y que en el caso concreto de Alonso de Cartagena es reflejo de las diferentes tradiciones culturales en las que se vio inmerso, entre la herencia de Aristóteles y el redescubrimiento de Platón, entre la tradición escolástica medieval y la influencia creciente del humanismo.

\section{Bibliografía citada}

AcCorsi, Federica, "La influencia de Alfonso de Cartagena en la Defensa de virtuosas mujeres de Diego de Valera", Estudios sobre la Edad Media, el Renacimiento y la temprana modernidad, Jimena Gamba Corradine (coord.), SEMYR - Cilengua, San Millán de la Cogolla, 2010, pp. 15-23.

Aguadé Nieto, Santiago, Libro y cultura italianos en la Corona de Castilla durante la Edad Media, Universidad de Alcalá, Alcalá de Henares, 1992.

Allen, Prudence, The Concept of Woman. The Aristotelian Revolution, 750 B.C. - A.D. 1250, William B. Eeerdmans Publishing Company, Michigan - Cambridge, 1997.

Allen, Prudence, The Concept of Woman. Volume II: The Early Humanist Reformation, 1250-1500, William B. Eeerdmans Publishing Company, Michigan - Cambridge, 2002. Alvar, Carlos, "Boccaccio en Castilla: entre recepción y traducción”, Cuadernos de Filología Italiana, número extraordinario (2001), pp. 333-350. 
Archer, Robert, Misoginia y defensa de las mujeres. Antología de textos medievales, Cátedra, Madrid, 2001.

Archer, Robert, The Problem of Woman in Late-Medieval Hispanic Literature, Tamesis, Woodbridge, 2005.

Benson, Pamela, "Debate about women in Trecento Florence", Gender in debate from the Early Middle Ages to the Renaissance, Thelma S. Fenster y Clare A. Lees (eds.), Palgrave, Nueva York, 2002, pp. 165-187.

Boccaccio, Giovanni, Mujeres preclaras, Cátedra, Madrid, 2010.

Bonilla Cerezo, Rafael, "Los monarcas del converso. Comentario bibliográfico", Artifara, 15 (2015), pp. 27-43.

Cantera Burgos, Francisco, Alvar García de Santa María y su familia de conversos. Historia de la Judería de Burgos y de sus conversos más egregios, Instituto Arias Montano, Madrid, 1952.

Cantera Montenegro, Enrique, "La mujer judía en la España medieval”, Espacio, Tiempo y Forma, Serie III, H. ${ }^{a}$ Medieval, 2 (1989), pp. 37-64.

de Cartagena, Alonso, Doctrinal de los caballeros, ed. José María Viña Liste, Universidade de Santiago de Compostela, Santiago de Compostela, 1995.

de Cartagena, Teresa, Arboleda de los enfermos. Admiraçión operum Dey, ed. Lewis Joseph Hutton, Real Academia Española, Madrid, 1967.

Castilla Urbano, Francisco, "La función de la metáfora organicista en la obra de Alonso de Cartagena”, Ingenium. Revista de historia del pensamiento moderno, 5 (enero-junio de 2011), pp. 77-103.

Castilla Urbano, Francisco, "Patriotismo y legitimación monárquica en el pensamiento de Alonso de Cartagena: los escritos de Basilea", Revista Española de Filosofía Medieval, 19 (2012), pp. 139-157.

CODERCH, Marion, “«Escapando de la molicie mujeril»: Virtudes femeninas y atributos de género en los tratados de defensa de las mujeres (siglos XIV y XV)", La Querella de las mujeres III. La Querella de las Mujeres antecedente de la polémica feminista, Cristina Segura Graíño (coord.), Almudayna, Sevilla, 2011, pp. 75-90.

Corfield, Penelope J., "History and the Challenge of Gender History", Rethinking History, 1:3 (1997), pp. 241-258.

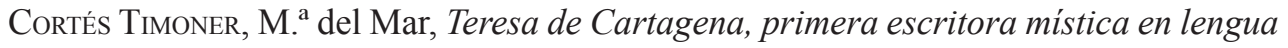
castellana, Universidad de Málaga, Málaga, 2004.

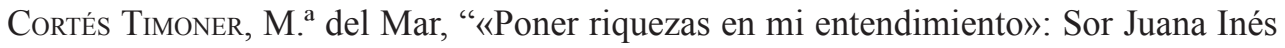
de la Cruz y Sor Teresa de Cartagena”, Lectora. Revista de dones i textualitat, 10 (2004), pp. 377-391.

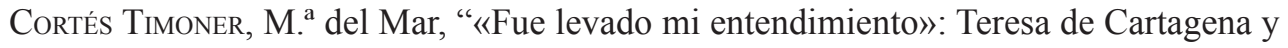
la escritura mística en femenino”, Scripta. Revista Internacional de Literatura i Cultura Medieval i Moderna, 8 (2016), pp. 148-163. 
Deyermond, Alan David, "El Convento de Dolencias: The Works of Teresa de Cartagena", Journal of Hispanic Philology, 1 (1976), pp. 19-29.

Di CAmillo, Ottavio, El humanismo castellano del siglo XV, ed. Fernando Torres, Valencia, 1976.

Di CAmillo, Ottavio, "Fifteenth-Century Spanish Humanism: Thirty-Five Years Later", La Corónica. A Journal of Medieval Hispanic Languages, Literatures \& Cultures, 39.1 (otoño 2010), pp. 19-66.

DuBy, Georges, El caballero, la mujer y el cura, Taurus, Madrid, 1999.

Fenster, Thelma S. y LeEs, Clare A., "Bibliography of Primary Texts in Spanish, ca. 1430-1520", Gender in debate from the Early Middle Ages to the Renaissance, Thelma S. Fenster y Clare A. Lees (eds.), Palgrave, Nueva York, 2002, pp. 275-282.

Fernández Gallardo, Luis, "En torno a los «studia humanitatis» en la Castilla del Cuatrocientos. Alonso de Cartagena y los autores antiguos", En la España Medieval, 22 (1999), pp. 213-246.

Fernández Gallardo, Luis, Alonso de Cartagena. Una biografía política en la Castilla del siglo XV, Junta de Castilla y León, Valladolid, 2002.

Fernández Gallardo, Luis, “Alonso de Cartagena y la escritura humanística: epístola y diálogo", Revista de poética medieval, 19 (2007), pp. 49-92.

Fernández Gallardo, Luis, "Las ideas políticas de Alonso de Cartagena”, Res Publica. Revista de filosofía política, 18 (2007), pp. 413-426.

Fernández Gallardo, Luis, “Alonso de Cartagena y el humanismo", La Corónica. A Journal of Medieval Hispanic Languages, Literatures \& Cultures, 37.1 (otoño 2008), pp. 175-215.

Fernández Gallardo, Luis, La obra literaria de Alonso de Cartagena (1385-1456). Ensayo de historia cultural, Editorial Académica Española, Saarbrücken, 2012.

FERNÁNDEZ GALLARDO, Luis, “Autotraducción y literatura devocional: la Apología sobre el salmo “Iudica me, Deus” de Alonso de Cartagena”, eHumanista, 28 (2014), pp. 576-595. Fernández Gallardo, Luis y Jiménez Calvente, Teresa, El Duodenarium (c. 1442) de Alfonso de Cartagena. Cultura castellana y letras latinas en un proyecto inconcluso, Córdoba, Almuzara, 2015.

FOURNÈs, Ghislaine, "De la traduction au manifeste politique: le Libro de las virtuosas e claras mugeres d'Álvaro de Luna", Cahiers d'études hispaniques medievales, 33 (2010), pp. 97-108.

GonzÁlez Rolán, Tomás, Moreno Hernández, Antonio y Saquero Suárez-Somonte, Pilar, Humanismo y teoría de la traducción en España e Italia en la primera mitad del siglo XV. Edición y estudio de la Controversia Alphonsiana (Alfonso de Cartagena vs. L. Bruni y P. Candido Decembrio), Ediciones Clásicas, Madrid, 2000. 
Hernández Amez, Vanesa, "Mujer y santidad en el siglo XV: Álvaro de Luna y El Libro de las Virtuosas E Claras Mugeres", Archivum: Revista de la Facultad de Filología, 52-53 (2002-2003), pp. 255-288.

Hussar, James, "The Jewish Roots of Teresa de Cartagena's Arboleda de los enfermos", La Corónica. A Journal of Medieval Spanish Language, Literature \& Cultural Studies, 35.1 (otoño 2006), pp. 151-170.

JimÉnez Calvente, Teresa, “Alonso de Cartagena y la cuarta cuestión del Duodenarium: hacia un ensayo del género del diálogo", eHumanista, 29 (2015), pp. 133-151.

KIM, Yonsoo, El saber femenino y el sufrimiento corporal de la temprana Edad Moderna. Arboleda de los enfermos y Admiraçión operum Dey de Teresa de Cartagena, Universidad de Córdoba, Córdoba, 2008.

KIm, Yonsoo, Between Desire and Passion: Teresa de Cartagena, Brill Academic, Leiden, 2012.

KIM, Yonsoo, "Representación de la ansiedad masculina como discurso de santidad en Teresa de Cartagena", Medievalia. Revista d'Estudis Medievals, 18,2 (2015), pp. 211-228.

KIM, Yonsoo y CARVAJAL, Anna María: "La codificación de la espiritualidad femenina de Teresa de Cartagena y Santa Teresa de Ávila”, eHumanista, 32 (2016), pp. 69-84.

KING, Margaret L., "Issota Nogarola, humanista y devota (1418-1488)", La mujer del Renacimiento, Ottavia Niccoli (ed.), Alianza Editorial, Madrid, 1993, pp. 35-64.

Louzada Fonseca, Pedro Carlos, "Difamación y defensa de la mujer en la Edad Media. Pasajes obligatorios”, Temas Medievales, 18 (2010), pp. 73-94.

DE LunA, Álvaro, Virtuosas e claras mugeres (año 1446), ed. Lola Pons Rodríguez, Instituto Castellano y Leonés de la Lengua, Segovia, 2008.

Marimón Llorca, Carmen, Prosistas castellanas medievales, Caja de Ahorros Provincial de Alicante, Alicante, 1990.

McGovern, Abby, "Writing the Antithesis of María of Aragón: Alvaro de Luna's Rendering of Giovanni Boccaccio's De mulieribus claris", Scripta. Revista Internacional de Literatura i Cultura Medieval i Moderna, 2 (2013), pp. 325-337.

Montoya Ramírez, M. ${ }^{a}$ Isabel, "Observaciones sobre la defensa de las mujeres en algunos textos medievales", Medioevo y literatura. Actas del V Congreso de la Asociación Hispánica de Literatura Medieval (Granada, 27 septiembre - 1 octubre 1993), Juan Paredes (ed.), Universidad de Granada, Granada, 1995, vol. 3, pp. 397-406.

Morrás Ruiz-Falcó, María, "Repertorio de obras, manuscritos y documentos de Alfonso de Cartagena (ca. 1384-1456)", Boletín Bibliográfico de la Asociación Hispánica de Literatura Medieval, 5 (1991), pp. 213-248.

Morrás Ruiz-Falcó, María, "Sic et non: En torno a Alfonso de Cartagena y los studia humanitatis", Evphrosyne. Revista de filología clásica, 23 (1995), pp. 333-346.

Morrás Ruiz-Falcó, María, "El debate entre Leonardo Bruni y Alonso de Cartagena: las razones de una polémica", Quaderns. Revista de traducció, 7 (2002), pp. 33-57. 
Niccoli, Ottavia (ed.), La mujer del Renacimiento, Alianza Editorial, Madrid, 1993. OÑATE, María Pilar, El feminismo en la literatura española, Espasa-Calpe, Madrid, 1938. ORNSTEIN, Jacob, "La misoginia y el profeminismo en la literatura castellana", Revista de Filología Hispánica, 3 (1941), pp. 219-232.

Pelaz Flores, Diana, “«A la más virtuosa de las mujeres». La reina María de Aragón (1420-1445) como impulsora de las letras en la Corona de Castilla", Hispania, 74, 247 (2014), pp. 331-356.

PRATT, Karen, "The strains of defense: the many voices of Jean Lefèvres Livre de Leesce", Gender in debate from the Early Middle Ages to the Renaissance, Thelma S. Fenster y Clare A. Lees (eds.), Nueva York, Palgrave, 2002, pp. 113-133.

RÁBAde OBradó, María del Pilar, "El arquetipo femenino en los debates intelectuales del siglo XV castellano”, En la España medieval, 11 (1988), pp. 261-286.

Ríos de la Llave, Rita, "Forget Your People and Your Father's House: Teresa de Cartagena and the Converso Identity", Historicizing Religion. Critical Approaches to Contemporary Concerns, Bojan Borstner y otros (eds.), Edizioni Plus - Università di Pisa, Pisa, 2010, pp. 41-54.

Ríos DE LA LlaVe, Rita, "Porque aunque a las mujeres les está proybido el predicar, no les está proybido aprender y leer y hablar en cosas de Dios, particularmente entre sí: La instrucción cristiana de las mujeres conversas en los siglos XV y XVI", eHumanista Conversos, 4 (2016), pp. 179-193.

Rivera Garretas, María Milagros, Textos y espacios de mujeres. Europa siglos $I V$-XV, Icaria, Barcelona, 1990.

Rivera Garretas, María Milagros, "La Admiración de las Obras de Dios de Teresa de Cartagena y la querella de las mujeres", La voz del silencio I (siglos VIII-XVIII), Cristina Segura Graíño (ed.), Al-Mudayna, Madrid, 1992, pp. 277-299.

Rivera Garretas, María Milagros, "Teresa de Cartagena la infinitud del cuerpo", Acta historica et archaeologica medievalia, 20 (1999), pp. 755-766.

Rivera Garretas, María Milagros (coord.), Las relaciones en la Historia de la Europa medieval, Tirant lo Blanch, Valencia, 2006.

Rivera Garretas, María Milagros, "Teresa de Cartagena vivía en 1478”, Estudios en memoria del profesor Dr. Carlos Sáez: Homenaje, M. ${ }^{a}$ del Val González de la Peña (coord.), Universidad de Alcalá, Alcalá de Henares, 2007, pp. 763-772.

Rivera Garretas, María Milagros, "Una vida en relación: Juana de Mendoza con Gómez Manrique, Isabel La Católica y Teresa de Cartagena", Vidas de mujeres del Renacimiento, Blanca Garí de Aguilera (coord.), Universitat de Barcelona, Barcelona, 2008, pp. 103-129.

Rivera Garretas, María Milagros, "Los dos infinitos en Teresa de Cartagena, humanista y mística del siglo XV”, Miscelánea Comillas, 69, 134 (2011), pp. 247-254. 
Rivera GarRetas, María Milagros, "La documentación de Teresa de Cartagena en Santa Clara de Burgos (1446-1452) y otros datos", La Corona catalano-aragonesa, l'Islam $i$ el món mediterrani: estudis d'història medieval en homenatge a la Doctora Maria Teresa Ferrer i Mallol, Josefina Mutge Vives, Roser Salicrú i Lluch y Carles Vela i Aulesa (eds.), CSIC, Barcelona, 2013, pp. 603-615.

Rodríguez del Padrón, Juan, Obras Completas, ed. César Hernández Alonso, Editora Nacional, Madrid, 1982.

Saquero SuÁrez-Somonte, Pilar y González Rolán, Tomás, "Actitudes renacentistas en Castilla durante el siglo XV: la correspondencia entre Alonso de Cartagena y Pier Cándido Decembrio", Cuadernos de Filología Clásica (Estudios Latinos), Universidad Complutense, Madrid, 1991, pp. 195-232.

SEIDENSPINNER-NunEZ, Dayle, "«Él solo me leyó»: Gendered Hermeneutics and Subversive Poetics in Admiraçión operum Dey of Teresa de Cartagena”, Medievalia, 15 (1993), pp. 14-23.

Seidenspinner-Nunez, Dayle, The Writings of Teresa de Cartagena, D. S. Brewer, Cambridge, 1998.

Seidenspinner-Nunez Dayle y Kim, Yonsoo, "Historicizing Teresa: reflections on new documents regarding Sor Teresa de Cartagena", La Corónica. A Journal of Medieval Spanish Language, Literature \& Cultural Studies, 32.2 (primavera 2004), pp. 121-150. Serrano, Florence, "La cuestión de la mujer y de la nobleza en la corte de Juan II de Castilla a la luz de los tratados de Juan Rodríguez del Padrón", Actas del XIII Congreso Internacional Asociación Hispánica de Literatura Medieval (Valladolid, 15 a 19 de septiembre de 2009). In memoriam Alan Deyermond, José Manuel Fradejas Rueda, Déborah Dietrick Smithbauer, Demetrio Martín Sanz y M. ${ }^{a}$ Jesús Díez Garretas (eds.), Asociación Hispánica de Literatura Medieval, Valladolid, 2010, vol. 2, pp. 1.667-1.679.

SERRANo, Florence, "Figures auctoriales et figures du pouvoir: Valera et Rodríguez del Padrón à la cour de Bourgogne", Cahiers d'études hispaniques medievales, 33 (2010), pp. 109-126.

SERrano, Florence, "Del debate de la propaganda política mediante la Querella de las mujeres en Juan Rodríguez del Padrón, Diego de Valera y Álvaro de Luna", Talia Dixit. Revista Interdisciplinar de Retórica e Historiografía, 7 (2012), pp. 97-115.

Solomon, Michael, The Literature of Misogyny in Medieval Spain. The Arcipreste de Talavera and the Spill, Cambridge University Press, Cambridge, 1997.

Surtz, Ronald E., Writing Women in Late Medieval and Early Modern Spain. The Mothers of Saint Teresa of Avila, Philadelphia, University of Pennsylvania Press, 1995. De VAlera, Diego, Defensa de virtuosas mujeres, ed. Federica Accorsi, Edizioni ETS, Pisa, 2009.

van Veen, Manon, "La mujer en algunas defensas del siglo XV: Diego de Valera y Juan Rodríguez del Padrón y los mecanismos de género", Medioevo y Literatura. Actas del 
V Congreso de la Asociación Hispánica de Literatura Medieval (Granada, 27 de septiembre - 1 de octubre de 1993), Juan S. Paredes Núñez (ed.), Universidad de Granada, Granada, 1995, vol. 4, pp. 465-472.

Vargas Martínez, Ana, La Querella de las mujeres. Tratados hispánicos en defensa de las mujeres (siglo XV), Editorial Fundamentos, Madrid, 2016.

VéLez-SaInz, Julio, La defensa de la mujer en la literatura hispánica. Siglos XV-XVII, Cátedra, Madrid, 2015.

Verdín-Díaz, Guillermo, Alonso de Cartagena y el Defensorium Unitatis Christianae, Universidad de Oviedo, Oviedo, 1992.

Walthaus, Rina, “«Gender», Revalorización y Marginalización: la Defensa de la Mujer en el Siglo XV", Actas do IV Congresso Wada Associação Hispânica de Literatura Medieval (Lisboa, 1-5 Outubro 1991), Aries A. Nascimento y Cristina Almeida Ribeiro (eds.), Edições Cosmos, Lisboa, 1993, vol. 4, pp. 269-274.

Weiss, Julian, "«¿Qué demandamos de las mugeres?»: Forming the Debate about Women in Late Medieval Spain (with a baroque response)", Gender in debate from the Early Middle Ages to the Renaissance, Thelma S. Fenster y Clare A. Lees (eds.), Palgrave, Nueva York, 2002, pp. 237-281. 
